Board of Governors of the Federal Reserve System

International Finance Discussion Papers

Number 671

July 2000

\title{
THE EFFECT OF MONETARY POLICY ON RESIDENTIAL AND STRUCTURES INVESTMENT UNDER DIFFERENTIAL PROJECT PLANNING AND COMPLETION TIMES
}

\author{
Rochelle M. Edge
}

NOTE: International Finance Discussion Papers are preliminary materials circulated to stimulate discussion and critical comment. References in publications to International Finance Discussion Papers (other than an acknowledgment that the writer has had access to unpublished material) should be cleared with the author or authors. Recent IFDPs are available on the Web at www.bog.frb.fed.us. 


\title{
THE EFFECT OF MONETARY POLICY ON RESIDENTIAL AND STRUCTURES INVESTMENT UNDER DIFFERENTIAL PROJECT PLANNING AND COMPLETION TIMES
}

\author{
Rochelle M. Edge*
}

\begin{abstract}
This paper analyzes an empirical puzzle regarding the effect of monetary policy on fixed investment, specifically, why residential investment exhibits a strong and rapid response to changes in monetary policy while structures investment manifests a substantially weaker response. The paper proposes an explanation for these contrasting responses that is based on the differential planning and completion times of these two categories of investment as well as inflexibilities in changing the planned pattern of investment spending once the project has begun. Empirical support for the explanation is established by contrasting the responses of U.S. residential and structures building project starts and work undertaken to a monetary policy shock. The paper then shows that a calibrated sticky-price monetary business cycle model with multistage investment projects is capable of generating responses to monetary policy that are broadly consistent with those observed empirically.
\end{abstract}

Keywords: transmission of monetary policy, residential investment, structures investment, time-to-build, time-to-plan.

\footnotetext{
* Mailstop 23, Federal Reserve Board, Washington DC 20551, (202) 452 2339; FAX: (202) 736-5638; rochelle.m.edge@frb.gov. I wish to thank Ben Bernanke and Michael Woodford for their advice and helpful comments, John Landon-Lane, Nathan Porter, Argia Sbordone, Robert Shimer, Chris Sims and Mark Watson for comments on earlier versions of this paper, and Kosuke Aoki and Jean Boivin for helpful conversations. I express my considerable gratitude to Jeremy Rudd for all of his help. All errors are my own. The views in this paper are solely the responsibility of the author and should not be interpreted as reflecting the views of the Board of Governors of the Federal Reserve System or of any other person associated with the Federal Reserve System.
} 
This paper examines a puzzling empirical regularity: In postwar U.S. data, residential investment exhibits a strong and rapid response to a monetary policy shock, while structures investment manifests a substantially weaker and slower response. This stylized fact is puzzling inasmuch as residential and structures investment both involve long-lived assets with very similar characteristics, so that one might expect them to manifest similar responses to monetary policy shocks.

Bernanke and Gertler (1995) have pointed out that the differential responses of residential and structures investment to changes in monetary policy can be explained by appealing to the so-called "bank-lending channel" of monetary policy transmission. ${ }^{1}$ While this explanation has some appeal, this paper argues that it is not the only possible explanation. As an alternative to the bank-lending channel, this paper accounts for the contrasting responses of residential and structures investment by focusing on, first, the differential planning and completion times of the building projects in these two categories of investment, and second, the inflexibilities that arise if firms attempt to change the planned pattern of investment spending once a project has begun. The former property of residential and structures investment is an important feature of real-world projects: The U.S. Bureau of the Census (1992, 1999b) estimates that nonresidential building projects take an average of fourteen months to complete (see table 1), while residential building projects, which are principally single-family houses, take an average of six and-a-half months to complete (see table 2).

To understand how long completion times can reduce the impact of a monetary shock on investment, consider the effects of a contractionary monetary shock. Long completion times coupled with inflexibilities in changing a planned pattern of investment may result in the continuation of projects already under construction even when a surprise monetary tightening has left them unprofitable in the sense that the cost of capital exceeds current rental rates. The option of doing zero overall investment and receiving a zero return with zero cost may not be available for a multistage project that is already underway; hence, even if an increase in interest rates leaves the project unprofitable, the other option-abandon the project and absorb the accumulated financing cost to date-might be even less attractive. The continuation of multistage building projects could therefore serve to prop up investment after a tightening in monetary policy, thus slowing and weakening investment's response to a monetary shock.

\footnotetext{
${ }^{1}$ Bernanke and Blinder's (1988) model of the bank-lending channel suggests that the open-market sales associated with a monetary tightening draw reserves and deposits away from the banking system, reducing the funds available to banks and thus curtailing the supply of bank loans. This can explain the responses of residential and structures investment to a monetary policy shock. Specifically, since households are typically bank dependent, a reduction in the volume of bank credit available to them will force them to curtail their spending. As households provide the final demand for residential investment, this will contract as monetary policy is tightened. Firms, on the other hand, are more capable of raising credit elsewhere; hence, structures investment-which is primarily undertaken by businesses - need not contract by as much following a monetary policy tightening.
} 
Long project-completion times also reduce the impact that temporary movements in real interest rates have on investment. The cost of capital for types of projects that require that investment spending be spread over multiple periods depends on the real interest rate over all the periods during which the spending takes place. A monetary tightening that raises real interest rates for only a few periods will, therefore, have a smaller effect on the overall cost of capital and hence on the resulting response of investment. This is the case both for projects under construction at the time of the shock as well as for projects not yet being built.

The relatively long completion times that characterize structures building projects thus imply a slower and weaker response to a monetary policy shock for structures investment than for residential investment.

This paper establishes support for the hypothesis that differential project planning and completion times account for the contrasting responses of residential and structures investment to monetary shocks. The first part of this paper seeks empirical support for this explanation, while the second part of the paper develops a theoretical model that is capable of generating the types of responses that are actually observed in the data.

The paper's empirical analysis involves examining the response of residential and structures starts and investment to a monetary policy shock. ${ }^{2}$ Structures and residential starts are included in the analysis for the reason that the existence of differential project planning and completion times also carries strong implications for the response of residential and structures starts. If the continuation of existing projects dampens the response of investment, structures and residential starts should both exhibit faster and stronger responses to monetary shocks than structures and residential investment. Furthermore, since long project-completion times are more a feature of structures building projects, the difference between the responses of structures starts and investment should be more pronounced than the difference between the responses of residential starts and investment. Finally, since long project-completion times suppress the effect of temporary movements in the real interest rate, the response of structures starts should be slower and weaker than residential starts. The inclusion of structures and residential starts thus provides an additional dimension along which to examine whether the available empirical evidence is consistent with the paper's hypothesis.

The empirical analysis, which is conducted by fitting vector autoregressions (VARs) to approximately two decades of monthly U.S. data, is organized as follows. Sections one and two describe the data and baseline vector autoregression models that will be used in the analysis. In section three, I include residential and structures investment in the VAR models of section two and establish that the basic finding - that residential investment exhibits a

\footnotetext{
${ }^{2}$ Starts are measured as the value of building projects commenced in a given period, while investment is the value of that portion of the project actually built during the period.
} 
strong and rapid response to monetary policy while structures investment displays little response at all-is robust across a number of specifications. Section four presents the paper's principal empirical findings. I find that structures and residential starts do indeed respond to changes in monetary policy more strongly and more rapidly than the corresponding components of investment, and also that the response of structures starts is slower and weaker than the response of residential starts. I do not find the difference between structures starts and investment to be any more pronounced than the difference between residential starts and investment. However, a refinement of the analysis for residential investment to consider only the responses of starts and investment in single-family homes does yield results that conform more closely to those implied by the paper's hypothesis. I conclude that the results of the VAR analysis are largely consistent with the paper's hypothesis. Furthermore, since the bank-lending channel explanation would (in the absence of differential project planning and completion times) predict the responses of residential and structures starts to be no different than the responses of their corresponding investment flows, the VAR analysis suggests that the bank-lending channel cannot, by itself, fully explain the behavior of residential and structures investment following a monetary shock.

The theoretical portion of the paper demonstrates that the empirical results can be replicated in the context of a calibrated model that incorporates two types of capital with differential planning and completion times in investment. Section five describes and discusses the basic variant of the sticky-price monetary business cycle model that I use. Section six describes how time-to-build, time-to-plan, and ex-post investment inflexibilities are added to the model. Section seven outlines the variant of the model that is employed to generate the paper's theoretical results, while section eight compares the responses generated from the theoretical model to those from the VAR systems. Section nine concludes by noting the paper's main results and discussing relevant policy implications.

\section{Data}

This section provides a brief overview of the data used in the vector autoregressions of sections two through five. (The data appendix contains a more detailed discussion.)

In order to assess better the timing of the various variables' responses to changes in monetary policy, I use monthly data in the VAR systems. For the basic VARs presented in section two, I require monthly estimates of output, prices, and commodity prices, together with a range of monetary policy variables that includes the Federal funds rate and nonborrowed and total reserves. Only the monetary policy variables and the commodity price series (the Dow-Jones index of spot commodity prices) are available at monthly frequencies; I therefore use Bernanke and Mihov's (1998) interpolated monthly estimates of real GDP 
and the GDP deflator in the VARs. ${ }^{3}$ In section three, I also use Bernanke and Mihov's interpolated monthly estimates of residential and structures investment.

In section four I require monthly measures of starts and value put in place for residential and structures construction. Value put in place data come from a survey that is conducted monthly by the U.S. Bureau of the Census, while starts data are taken from unpublished monthly data compiled by the F.W. Dodge Group, a private consulting firm. ${ }^{4}$ The Census data are seasonally adjusted, but I must seasonally adjust the F.W. Dodge data myself. ${ }^{5}$ Once again, all series are measured in constant 1992 dollars.

The sample period used in this study is from July 1976 to December 1996. While a longer history is available, the shortened sample period is preferable because of changes in data construction methods. This issue is discussed in greater detail in the data appendix.

\section{Overview of the VAR Systems}

This section briefly considers five core VAR systems that will be used to analyze the effect of monetary policy on residential and structures investment. Considering a range of VARs is necessary given the lack of consensus among researchers as to the variable (or variables) the Fed controls in setting monetary policy; similar disagreement also exists regarding the composition of the Fed's information set at the time monetary policy decisions are made. It is therefore important to assess how robust the results of this paper are to different monetary policy identification methods.

I consider three types of models. The first assumes that the Fed's monetary policy instrument is the Federal funds rate; the second assumes that the policy instrument is the level of nonborrowed reserves; and the third uses the Bernanke-Mihov (1998) method of identification (which, for the just-identified case, requires no assumptions as to the Fed's policy instrument). The VARs also include variables that are contained in the Fed's information set (but not otherwise incorporated in the VAR) in order to permit the identification of "true" monetary policy shocks. Each VAR contains measures of output and prices (real

\footnotetext{
${ }^{3}$ Bernanke and Mihov (1998) construct monthly estimates of real GDP, its major expenditure components, and the GDP deflator using a Kalman filter and a number of monthly partial indicators. Details of the interpolation method as well as the monthly series employed in the estimation procedure can be found in the appendices to Bernanke and Mihov (1998) and Bernanke, Gertler, and Watson (1997). The real series used in my VARs are all seasonally adjusted and measured in constant 1992 prices.

${ }^{4}$ Although the starts and value put in place data come from different sources, they are actually closely related over the sample period used in this study. (See the data appendix for details.)

${ }^{5}$ I use the RATS econometric package's exponential smoothing algorithm to seasonally adjust the F.W. Dodge starts data. This process begins by estimating a set of seasonal factors (using dummy variables) which are then iterated upon so as to arrive at a final set of factors. This final set of seasonal factors maximizes the smoothness of the seasonally adjusted series while also minimizing the year to year variability of the seasonal factors.
} 
GDP and the GDP deflator); following Sims (1992), the VARs also include a measure of commodity prices. ${ }^{6}$

Using the Federal funds rate to measure the Fed's policy stance is informed by the work of Bernanke and Blinder (1992), who find that the Federal funds rate outperforms several candidate indicators of monetary policy. The first VAR system that I estimate (referred to as Federal funds rate system I) includes four variables: real GDP, the GDP deflator, commodity prices, and the Federal funds rate. ${ }^{7}$ I order the Federal funds rate last, the implication being that current levels of output, the price level, and commodity prices are known by the Fed when it sets monetary policy (a related implication is that output and prices do not respond immediately to a monetary policy shock).

I also consider a variant of the Federal funds rate-based VAR that allows several other variables (specifically, lagged values of total reserves, nonborrowed reserves, and the money supply) to enter the Fed's information set. I therefore estimate a seven-variable VAR (referred to as Federal funds rate system II) that includes the same variables as the fourvariable specification, along with the three additional variables that are placed after the Federal funds rate in the VAR ordering. ${ }^{8}$

Using nonborrowed reserves to measure the Fed's policy stance is informed by the work of Christiano and Eichenbaum (1992), who argue that nonborrowed reserves are most directly controlled by the Fed in conducting monetary policy. The first variant of the nonborrowed reserves-based VAR systems (referred to as nonborrowed reserves system I) that I consider assumes that the Fed's information set is identical to that used in the second Federal fundsbased VAR. The only difference in this specification is that the nonborrowed reserves term is placed before the Federal funds rate in the VAR ordering.

Strongin (1995) has argued that, since the demand for total reserves is completely interest-inelastic in the short run, a shock to nonborrowed reserves should leave total reserves unchanged in the initial period, and only affect its division between borrowed and nonborrowed reserves. The second variant of the nonborrowed reserves-based VAR systems (referred to as nonborrowed reserves system II) therefore places total reserves ahead of nonborrowed reserves in the VAR ordering.

Bernanke and Mihov (1998) embed the structure of the Federal funds market in their VAR and use it to identify monetary policy shocks. The VAR used for this method of

\footnotetext{
${ }^{6}$ Sims (1992) argues that the central bank's information set may contain information about future inflation, such as whether an oil price shock has occurred. Ignoring this can give rise to the so-called "price puzzle," in which prices increase following a monetary tightening. Intuitively, the price puzzle occurs because we have confounded an endogenous change in the monetary policy instrument with an exogenous change in policy.

${ }^{7}$ Real GDP, the GDP deflator, and the measure of commodity prices enter the VARs in log-levels while the Federal funds rate enters in levels.

${ }^{8}$ Total and nonborrowed reserves are normalized by a 36-month moving average of total reserves while M2 is expressed in real terms and enters in log-levels.
} 
identification (referred to as the Federal funds market system) does not include the real money supply but otherwise contains the same variables as the VARs under the three previous identification methods. The three policy variables are ordered last in the VAR.

All five VAR systems examined in this section yield plausible qualitative responses for output and prices (not shown) following a monetary policy shock; furthermore, the response of prices does not seem to suffer too greatly from the "price puzzle." 9 The responses of output and prices in the two Federal funds rate-based VARs are noticeably smaller and slower than the responses obtained from the other three VARs. Estimates of the standard error bands in the Federal funds market system (not shown) are extremely large, leaving the responses of all variables insignificant for all periods following the shock. ${ }^{10}$ The insignificance of the impulse response functions following a monetary policy shock when this method of identification is used arises repeatedly in subsequent sections. ${ }^{11}$ Nevertheless, in what follows I employ all five specifications in order to assess the robustness of my empirical results to my choice of monetary policy instrument.

\section{The Response of Residential and Structures Investment to a Monetary Policy Shock}

This section establishes the basic stylized fact that this paper seeks to explain: Following a monetary tightening, residential investment activity manifests a sharp and nearly immediate decline, while structures investment exhibits a substantially slower and weaker response.

I establish this result by adding real residential and structures investment to the VAR systems of section two. ${ }^{12}$ Panels (a) and (b) of figure 1 plot the relevant impulse response functions. ${ }^{13}$

In subsequent sections I find it preferable to use the Census Bureau's value put in place

\footnotetext{
${ }^{9}$ In order to conserve degrees of freedom given a sample of a little over 20 years, I estimate the VARs in this paper assuming 6 lags of each variable. The impulse response functions resulting from VARs with longer or shorter lag structures remain qualitatively unchanged.

${ }^{10}$ All standard error bands reported in this paper have been computed using the Bayesian Monte Carlo method that is provided with the RATS econometric package.

${ }^{11}$ Waggoner and Zha (1997) have pointed out that the posterior distributions of impulse response functions can be sensitive to different normalization rules; consequently, inappropriate normalization rules can generate impulse responses that appear to be statistically insignificant. In particular, Waggoner and Zha demonstrate the applicability of this result to the identification of monetary policy shocks. Hence, a possible explanation for the insignificance of the impulse response functions reported here is that the standard error bands are affected by the use of an inappropriate normalization rule.

${ }^{12}$ Both investment measures are expressed in logarithms and are placed immediately after real GDP in the VAR ordering.

${ }^{13}$ All impulse response functions presented in this paper (from both the empirical and the theoretical models) are normalized so as to yield an immediate 50 basis point increase in the annualized Federal funds rate.
} 
estimates as the measure of investment rather than the gross fixed investment estimates from the national accounts. ${ }^{14}$ I therefore also show, in panels (c) and (d) of figure 1, the relevant responses when value put in place is the measure of investment in the VARs.

The left-hand panels of figure 1 indicate that residential investment (and value put in place) falls sharply following a monetary tightening. The magnitude of the initial decline as well as the timing and persistence of the decline differs across specifications. The responses of residential investment and value put in place are found to be statistically significant under all identification schemes except the Federal funds market-based method.

The responses of structures investment and value put in place are plotted in the righthand panels of figure 1. For each method of identification the response of structures investment or value put in place to a monetary policy shock is noticeably smaller and slower than the corresponding response of residential investment or value put in place. For the Federal funds rate identification schemes the responses of residential and structures investment or value put in place are significantly different to each other for the first eighteen months following the shock. For the nonborrowed reserves identification schemes the responses are significantly different to each other for the first six months. The responses of structures investment and value put in place, in all cases, are found to be statistically insignificant. ${ }^{15}$

\section{Comparing the Responses of Value Put in Place and Starts to Monetary Policy Shocks}

The preceding section replicated the previous finding of several authors that residential investment contracts sharply following a monetary tightening while structures investment displays a slower and more subdued response. I now examine the behavior of residential and structures starts and value put in place following a monetary policy shock.

The left-hand panels of figure 2 display the estimated responses of structures value put in place and starts following a monetary tightening. ${ }^{16}$ The impulse response functions all

\footnotetext{
${ }^{14}$ The Census Bureau's value put in place series is preferred as the measure of investment (as opposed to the national accounts measures) since its coverage is exactly the same as that of the F.W. Dodge starts series that is used in the following section. Value put in place and investment are identical concepts in principle, but in practice-i.e., as measured in the national accounts-they differ. Given that I wish to compare the responses of starts and investment and to attribute their differences to the continuation of existing projects, it is preferable that I have measures of starts and investment that are conceptually as similar as possible.

${ }^{15}$ The results in figure 1 remain largely unchanged when residential investment and structures investment are added together to each VAR system or when longer or shorter lag structures are assumed in the VARs.

${ }^{16}$ These variables are entered together as logs and placed immediately after real GDP in the VAR ordering. The impulse response functions presented in figure 2 are generated by VAR systems that include both structures value put in place and structures starts. The response of structures value put in place is not invariant to whether it is added individually (figure 1) or together with structures starts (figure 2) to the VAR; the response of structures starts is largely invariant to whether it is added individually (not shown)
} 
indicate that structures starts contract following a monetary tightening; moreover, structures value put in place manifests a smaller and slower response in all cases save the one that employs the Federal funds market method of identification. These responses are statistically significant from zero for all of the systems except the one that uses the Federal funds market method of identification and are significantly different to each other at the 10 percent significance level for the first six months following the shock in the Federal funds rate identification schemes. The results conform with the prediction that the continuation of large multistage projects serves to prop up structures investment following a monetary tightening. ${ }^{17}$

The middle panels of figure 2 plot the corresponding results for residential value put in place and starts. In all specifications the response of residential starts is larger and more rapid than the response of residential value put in place. In all cases, except for the Federal funds market method of identification, the negative responses of residential starts and value put in place are significantly different from zero and are significantly different to each other at the 5 percent significant level for the first six months following the shock. These results also indicate that the response of residential investment following a monetary tightening is dampened by the continuation of existing residential building projects.

Since long project-completion times are more a feature of structures building projects, the paper's hypothesis would predict that the difference between the responses of structures starts and value put in place should be more pronounced than the difference between the responses of residential starts and investment. This prediction is not supported by the responses presented in the first two columns of figure 2. However, when the multifamily homes are removed from aggregate residential buildings, so leaving only single-family homes, the difference between the responses of starts and value put in place (given in the right-hand panels of figure 2) become smaller. This suggests that much of the difference between the responses of residential starts and value put in place is accounted for by the continuation of longer-duration building projects in multifamily homes.

The empirical findings presented in figure 2 offer general support for the notion that the continuation of large multistage investment projects can account for the differential response of residential and structures investment to changes in monetary policy. ${ }^{18}$ The very similar responses of structures starts and value put in place that result when the Federal funds market method of identification is used does contradict the paper's hypothesis; however, given, however, that this method of identification appears to encounter substantial difficulties in producing significant responses over the 1976 to 1996 sample period, my inclination is to focus on the impulse response functions that obtain from the other four

or together with structures value put in place (figure 2).

${ }^{17}$ The estimated impulse response functions are robust to the removal of the not-for-profit components of structures investment (such as religious and educational buildings and hospitals).

${ }^{18}$ Again, the results in this section are qualitatively robust to changes in the assumed lag length. 
methods of identification. ${ }^{19}$

The responses of residential and structures starts following a monetary policy shock can also be compared in figure 2. The figure shows that the response of structures starts following a monetary policy tightening is smaller and slower than the corresponding response for residential starts. This result can be explained by the fact that the cost of capital for projects with long completion times is less affected by temporary movements in real interest rates than that for projects with shorter completion times. This results in a more subdued response to monetary policy for projects with longer completion times and so would explain why the response of structures starts is slower and weaker than that of residential starts. A further interpretation is that it reflects different project planning times between residential and structures investment.

While the empirical results conform with the predictions of the paper's hypothesis, it is not clear from looking only qualitatively at the empirical results whether the paper's proposed explanation based on differential project planning and completion times can fully account for the observed responses of residential and structures investment to changes in monetary policy. For example, while the VAR analysis finds that the bank-lending channel cannot, by itself, fully explain the behavior of residential and structures investment, ${ }^{20}$ the fact that residential starts respond more strongly than structures starts might still imply an explanatory role for the bank-lending channel, even if it is in conjunction with an explanation based on differential project planning and completion times. This issue can best be addressed in the context of a theoretical model with separate capital stocks involving different project planning and completion times.

\section{The Benchmark Sticky-Price Monetary Business Cycle Model}

Having established a degree of empirical support for the paper's hypothesis that differential project planning and completion times between residential and structures investment projects can account for their contrasting responses to monetary policy shocks, I next consider whether it is possible to explain the empirical results in the context of a calibrated theoretical model. This section outlines the benchmark model around which this analysis is built.

\footnotetext{
${ }^{19}$ Bernanke and Mihov (1998) note that there is considerable instability in the structural parameter estimates under the just-identified method of identification, which they attribute to monetary policy regime changes. Given that the 1976 to 1996 sample used in this paper contains two dramatic regime changes, one might expect sizeable standard errors on parameter estimates, which would in turn result in large standard errors on the impulse response functions. To test this conjecture I reestimated the VAR over the sample February 1984 to December 1996, which does not involve any obvious regime shifts. The large standard errors around the impulse response functions persist, however.

${ }^{20}$ The bank-lending channel would predict the responses of residential and structures starts to be no different to the responses of their investment counterparts.
} 
A model used to replicate the paper's empirical results requires two types of capital. In order to incorporate two types of capital, I follow the household production branch of the real business cycle literature and assume two types of consumption goods: household goods (which are produced and consumed by the representative household without going through the market) and market goods (which are produced by firms, consumed by the household, and thus traded through a market). Two types of capital then enter the model from the assumption that the capital used in the production process is sector specific. The capital used for market production is interpreted as structures capital while the capital used for household production is interpreted as residential capital. For the time being, I assume that the capital used in both production processes takes only one period to build and involves no planning time. Time-to-build, time-to-plan, and ex-post investment inflexibilities are added in section six. ${ }^{21}$

The economy is characterized by the following set of agents: a continuum of monopolistically competitive intermediate-good producing firms, each of which hires labor and capital to produce a differentiated product for which they set the price (so meeting demand at the posted price) $;^{22}$ a competitive representative final-good producing firm which uses all of the differentiated intermediate goods to produce a final composite market good that is used for consumption and investment in the economy; a representative household, who consumes some of the final market good, consumes and produces the household good, holds money balances to finance transactions, supplies labor and rents capital to firms, and undertakes investment in both types of the economy's capital stock; and a monetary authority who sets an interest rate according to a generalized feedback rule.

\subsection{Setup of the Model}

\subsubsection{Consumers}

The household sector of the economy is characterized by an infinitely lived representative household with preferences defined over both types of consumption, holdings of real money balances, and total hours worked:

$$
U_{0}=E_{0}\left\{\sum_{t=0}^{\infty} \beta^{t}\left[\ln \left(C_{t}\right)+\xi \ln \left(\frac{M_{t}}{P_{t}}\right)-\left(\frac{1}{1+s}\right)\left(H_{t}^{Y}+H_{t}^{D}\right)^{1+s}\right]\right\}
$$

where

$$
C_{t}=\left[a\left(C_{t}^{Y}\right)^{e}+(1-a)\left(C_{t}^{D}\right)^{e}\right]^{\frac{1}{e}}
$$

\footnotetext{
${ }^{21}$ Gomme, Kydland, and Rupert (2000) have also embedded time-to-build in a household production model to study movements in household and business investment over the business cycle.

${ }^{22}$ Differentiated products are necessary in this context since they provide firms with some degree of market power, in turn allowing them to set prices that differ from the competitive market-clearing level.
} 
and $-\infty<e \leq 1$. $C_{t}^{Y}$ is the household's consumption of the market good, $C_{t}^{D}$ is the consumption of the household-produced good, and $\frac{M_{t}}{P_{t}}$ is the household's holding of real money balances. The utility function implies that supplying labor as an input into marketproduced goods $\left(H_{t}^{Y}\right)$ and supplying labor as an input into the household-produced good $\left(H_{t}^{D}\right)$ yield the same disutility. The parameters $\beta$ and $s$ denote the consumer's discount factor and the inverse of its elasticity of intertemporal labor substitution, while $\xi, a$, and $e$ represent other preference parameters. ${ }^{23}$

This model is typical of the household production literature in that it assumes that only the market good is used for investment. That is, output of the market good $\left(Y_{t}\right)$ can be consumed $\left(C_{t}^{Y}\right)$, used to build new capital for the production of market goods $\left(I_{t}^{Y}\right)$, or used to build new capital for the production of household goods $\left(I_{t}^{D}\right)$. The household good, however, can only be consumed $\left(C_{t}^{D}\right)$. Given the constant-returns-to-scale production function for the household good, this implies that:

$$
C_{t}^{D}=\left(K_{t}^{D}\right)^{\eta}\left(H_{t}^{D}\right)^{(1-\eta)}
$$

where $K_{t}^{D}$ is the capital stock used for household production and $\eta$ is the (constant) elasticity of output with respect to capital. ${ }^{24}$

Since both investment goods are bought through the market the household's flow budget constraint is:

$$
B_{t}+M_{t} \leq R_{t-1} B_{t-1}+M_{t-1}+\omega_{t} H_{t}^{Y}+\rho_{t} K_{t}^{Y}+\text { profits }_{t}-T_{t}-P_{t} C_{t}^{Y}-P_{t} I_{t}^{Y}-P_{t} I_{t}^{D} .
$$

Here $B_{t}$ and $M_{t}$ denote the household's end-of-period $t$ holdings of nominal bonds and money, while $K_{t}^{Y}$ denotes the household's holdings of real market capital at the start of period t; $R_{t}$ is the gross quarterly nominal interest rate; $\omega_{t}$ and $\rho_{t}$ denote the nominal wage and rental rate, respectively; $T_{t}$ is nominal net government transfers to the household; and $P_{t}$ is the price of the final good.

The household owns both types of capital stock in the economy; these evolve according to:

$$
K_{t+1}^{Y}=\left(1-\delta_{Y}\right) K_{t}^{Y}+K_{t}^{Y} J_{Y}\left(\frac{I_{t}^{Y}}{K_{t}^{Y}}\right)
$$

\footnotetext{
${ }^{23}$ In setting up the sticky-price monetary business cycle model I loosely follow the approach of Yun (1996). In setting up the household production part of the model I loosely follow Greenwood, Rogerson, and Wright (1994).

${ }^{24}$ In all, there will be two sources of asymmetry between the model's treatment of market and household goods. The first arises from the fact that only the market good is used for investment (see Greenwood and Hercowitz (1991) for a discussion of this point). A second asymmetry, which will be seen when the production side of the economy is presented, arises from the assumption that the price of the market good is sticky while the shadow price of the household good is perfectly flexible.
} 


$$
K_{t+1}^{D}=\left(1-\delta_{D}\right) K_{t}^{D}+K_{t}^{D} J_{D}\left(\frac{I_{t}^{D}}{K_{t}^{D}}\right)
$$

where $\delta_{Y}$ and $\delta_{D}$ are the rates of depreciation of the market and household capital stocks, and $K_{t}^{j} J_{j}\left(\frac{I_{t}^{j}}{K_{t}^{j}}\right)$ describes the adjustment costs for changing each capital stock. Following Hayashi (1982), the function $J_{j}($.$) is assumed to have the properties J_{j}\left(\delta_{j}\right)=\delta_{j}, J_{j}^{\prime}\left(\delta_{j}\right)=1$, and $J_{j}^{\prime \prime}\left(\delta_{j}\right) \leq 0$. Note that the evolution equations imply that the capital stock in any period is known as of the preceding period.

The household chooses $\left\{C_{t}^{Y}, C_{t}^{D}, \frac{M_{t}}{P_{t}}, H_{t}^{Y}, H_{t}^{D}, K_{t+1}^{Y}, K_{t+1}^{D}\right\}_{t=0}^{\infty}$ to maximize its utility (equation (1)) subject to its budget constraint (equation (3)) and the capital evolution equations ((4) and (5)). The utility-maximization problem yields the following first-order conditions for the household: ${ }^{25}$

$$
\begin{gathered}
\left(\frac{\partial C_{t}}{\partial C_{t}^{Y}}\right)\left(\frac{1}{C_{t} P_{t}}\right)=R_{t} \beta E_{t}\left[\left(\frac{\partial C_{t+1}}{\partial C_{t+1}^{Y}}\right)\left(\frac{1}{C_{t+1} P_{t+1}}\right)\right] \\
\frac{\xi C_{t}}{1-R_{t}^{-1}}=\left(\frac{\partial C_{t}}{\partial C_{t}^{Y}}\right)\left(\frac{M_{t}}{P_{t}}\right) \\
\left(H_{t}^{Y}+H_{t}^{D}\right)^{s}=\widetilde{\omega}_{t}\left(\frac{\partial C_{t}}{\partial C_{t}^{Y}}\right)\left(\frac{1}{C_{t}}\right) \\
\left(H_{t}^{Y}+H_{t}^{D}\right)^{s}=\left(\frac{1}{C_{t}}\right)\left(\frac{\partial C_{t}}{\partial C_{t}^{D}}\right)\left(\frac{\partial C_{t}^{D}}{\partial H_{t}^{D}}\right) \\
E_{t}\left[-\frac{R_{t}}{\Pi_{t+1}} J_{Y}^{-1^{\prime}}\left(\left(\frac{K_{t+1}^{Y}}{K_{t}^{Y}}\right)^{-}\left(1-\delta_{Y}\right)\right)+\widetilde{\rho}_{t+1}\right] \\
=E_{t}\left[J_{Y}^{-1}\left(\left(\frac{K_{t+2}^{Y}}{K_{t+1}^{Y}}\right)-\left(1-\delta_{Y}\right)\right)-J_{Y}^{-1^{\prime}}\left(\left(\frac{K_{t+2}^{Y}}{K_{t+1}^{Y}}\right)-\left(1-\delta_{Y}\right)\right)\left(\frac{K_{t+2}^{Y}}{K_{t+1}^{Y}}\right)\right] \\
E_{t}\left[-\frac{R_{t}}{\Pi_{t+1}} J_{D}^{-1^{\prime}}\left(\left(\frac{K_{t+1}^{D}}{K_{t}^{D}}\right)-\left(1-\delta_{D}\right)\right)+\frac{\left(\frac{\partial C_{t+1}}{\partial C_{t+1}^{D}}\right)\left(\frac{\partial C_{t+1}^{D}}{\partial K_{t+1}^{D}}\right)}{\left(\frac{\partial C_{t+1}}{\partial C_{t+1}^{Y}}\right)}\right] \\
E_{t}\left[J_{D}^{-1}\left(\left(\frac{K_{t+2}^{D}}{K_{t+1}^{D}}\right)-\left(1-\delta_{D}\right)\right)-J_{D}^{-1^{\prime}}\left(\left(\frac{K_{t+2}^{D}}{K_{t+1}^{D}}\right)-\left(1-\delta_{D}\right)\right)\left(\frac{K_{t+2}^{D}}{K_{t+1}^{D}}\right)\right]
\end{gathered}
$$

where the (gross) quarterly inflation rate is:

\footnotetext{
${ }^{25}$ In what follows, a tilde over a variable distinguishes the variable's real value from its nominal counterpart.
} 


$$
\Pi_{t}=\frac{P_{t}}{P_{t-1}}
$$

The first-order conditions have the standard interpretations. ${ }^{26}$

\subsubsection{Final-Good Producers}

The representative final-good producing firm uses all of the differentiated intermediate goods to produce a composite final good which is used for consumption and investment. The production function for $Y_{t}$ takes the standard Dixit-Stiglitz (1977) form:

$$
Y_{t}=\left(\int_{0}^{1} Y(z)_{t}^{\frac{\theta-1}{\theta}} d z\right)^{\frac{\theta}{\theta-1}}
$$

where $Y_{t}(z)$ is the quantity of the differentiated good $z$ that the final-good producer demands and $\theta$ is the elasticity of substitution in production.

The final-good producing firm chooses $\left\{Y(z)_{t} \forall z \in[0,1]\right\}_{t=0}^{\infty}$ so as to minimize costs given the set of prices $\left\{P(z)_{t} \forall z \in[0,1]\right\}_{t=0}^{\infty}$ posted by the intermediate-good producers. This yields a demand function for each of the intermediate goods, given by:

$$
Y(z)_{t}=Y_{t}\left(\frac{P(z)_{t}}{P_{t}}\right)^{-\theta}
$$

The demand functions for the intermediate goods imply that the competitive price $P_{t}$ for the final good is given as:

$$
P_{t}=\left(\int_{0}^{1} P(z)_{t}^{1-\theta} d z\right)^{\frac{1}{1-\theta}}
$$

\subsubsection{Intermediate-Goods Producers}

The intermediate-goods sector is composed of a continuum of monopolistically competitive firms who each hire labor and rent capital competitively from the household but set the price of their differentiated good subject to the demand curve that they face for their product.

The intermediate-goods producing firms each choose $\left\{H(z)_{t}, K(z)_{t}^{Y}\right\}_{t=0}^{\infty}$ to minimize their production costs given the following Cobb-Douglas production function:

$$
Y(z)_{t}=\left(K^{Y}(z)_{t}\right)^{\alpha}\left(H^{Y}(z)_{t}\right)^{(1-\alpha)}-F C
$$

\footnotetext{
${ }^{26}$ Equation (6) is the intertemporal IS equation, equation (7) is the LM equation, equation (8) is the household's labor supply to the market, equation (9) is the labor supply to domestic production, equation (10) defines the household's supply of capital to the market in the following period, and equation (11) defines the supply of capital to domestic production in the following period.
} 
where $\alpha$ is the elasticity of output with respect to capital and $F C$ represents a fixed cost faced by the firm.

The firms' cost-minimization problem yields the following set of factor demands:

$$
\begin{gathered}
H^{Y}(z)_{t}=\left(\frac{1-\alpha}{\alpha}\right)^{\alpha}\left(Y(z)_{t}+F C\right)\left(\frac{\widetilde{\rho}_{t}}{\widetilde{\omega}_{t}}\right)^{\alpha} \\
K^{Y}(z)_{t}=\left(\frac{\alpha}{1-\alpha}\right)^{1-\alpha}\left(Y(z)_{t}+F C\right)\left(\frac{\widetilde{\omega}_{t}}{\widetilde{\rho}_{t}}\right)^{1-\alpha}
\end{gathered}
$$

and total and marginal cost functions:

$$
\begin{gathered}
\widetilde{T C}(z)_{t}=\left(Y(z)_{t}+F C\right)\left(\frac{\widetilde{\omega}_{t}}{1-\alpha}\right)^{1-\alpha}\left(\frac{\widetilde{\rho}_{t}}{\alpha}\right)^{\alpha} \\
\widetilde{M C}(z)_{t}=\left(\frac{\widetilde{\omega}_{t}}{1-\alpha}\right)^{1-\alpha}\left(\frac{\widetilde{\rho}_{t}}{\alpha}\right)^{\alpha} .
\end{gathered}
$$

Firms choose the price of their differentiated good, $P(z)_{t}$, to maximize profits given their cost function and demand curve.

The model developed in this paper uses a specification of price stickiness due to Calvo (1983) in order to generate real and persistent effects of monetary policy on real output. Calvo pricing assumes that in each period a proportion $(1-\gamma)$ of firms will be able to change their prices while the remaining $\gamma$ will be constrained to charge the previous period's price regardless of the time elapsed since the last time they changed their price. I further assume that when prices are reset they are done so one period in advance, which implies that the economy-wide price level (and hence the inflation rate) is known one period in advance. The firms' profit-maximization problem therefore involves choosing $\left\{P(z)_{t}\right\}_{t=1}^{\infty}$ to maximize the present discounted value of profits, defined as:

$$
\sum_{k=0}^{\infty} \gamma^{k} \beta^{k+1} E_{t}\left[\frac{\lambda_{t+k+1}}{\lambda_{t}}\left(\left(\frac{P(z)_{t+1}}{P_{t+k+1}}-\frac{M C(z)_{t+k+1}}{P_{t+k+1}}\right) Y(z)_{t+k+1}-F C\right)\right]
$$

subject to equation (13), where $\lambda_{t}$ denotes the marginal utility of consumption in period $t$. For firms who do change their prices in period $t$, the profit-maximization problem implies a price of:

$$
E_{t}\left[P(z)_{t+1}\right]=\frac{\sum_{k=0}^{\infty} \gamma^{k} \beta^{k+1} E_{t}\left[\lambda_{t+k+1} \frac{M C_{t+k+1}}{P_{t+k+1}} \theta Y(z)_{t+k+1}\right]}{\sum_{k=0}^{\infty} \gamma^{k} \beta^{k+1} E_{t}\left[\lambda_{t+k+1} \frac{1}{P_{t+k+1}}(\theta-1) Y(z)_{t+k+1}\right]} .
$$

Economy-wide factor demand schedules are derived by integrating the individual firms' factor demands over the unit interval: 


$$
\begin{gathered}
H_{t}^{Y}=\left(\frac{1-\alpha}{\alpha}\right)^{\alpha}\left(Y_{t}\left(\int_{0}^{1}\left(\frac{P_{t}(z)}{P_{t}}\right)^{-\theta} d z\right)^{-\frac{1}{\theta}}+F C\right)\left(\frac{\widetilde{\rho}_{t}}{\widetilde{\omega}_{t}}\right)^{\alpha} \\
K_{t}^{Y}=\left(\frac{\alpha}{1-\alpha}\right)^{1-\alpha}\left(Y_{t}\left(\int_{0}^{1}\left(\frac{P_{t}(z)}{P_{t}}\right)^{-\theta} d z\right)^{-\frac{1}{\theta}}+F C\right)\left(\frac{\widetilde{\omega}_{t}}{\widetilde{\rho}_{t}}\right)^{1-\alpha} .
\end{gathered}
$$

With all firms facing the same wage and rental rates, economy-wide marginal cost is equal to the marginal cost of an individual firm, which is given by equation (15). The economy-wide price level is determined in the final-goods market by equation (14).

\subsubsection{Monetary Authority}

The monetary authority operates according to a monetary feedback rule that is in the spirit of a "Taylor rule." Specifically, the monetary authority sets nominal interest rates in response to variations of output and inflation away from their steady-state levels, but at the same time aims to smooth movements in the interest rate. I use a monetary policy rule similar to the one employed by Bernanke, Gertler, and Gilchrist (1999). This rule is defined as:

$$
R_{t}=\left(R_{t-1}\right)^{\rho_{R}}\left(Y_{t}^{\phi_{Y}} \Pi_{t}^{\phi_{\Pi}}\right)^{1-\rho_{R}} e^{\varepsilon_{t}}
$$

where $\varepsilon_{t}$ represents the stochastic component of the rule.

\subsubsection{Market Clearing}

A final condition for the model is market clearing, that is, the volume of consumption and investment undertaken in any period must be equal to the volume of output produced, or

$$
C_{t}^{Y}+I_{t}^{Y}+I_{t}^{D}=Y_{t}
$$

\subsection{Equilibrium}

Equilibrium is an allocation $\left\{C_{t}^{Y}, \frac{M_{t}}{P_{t}}, H_{t}^{Y}, H_{t}^{D}, K_{t+1}^{Y}, K_{t+1}^{D}, Y_{t}\right\}_{t=0}^{\infty}$ and a sequence of values $\left\{\Pi_{t+1}, \widetilde{\omega}_{t}, \widetilde{\rho}_{t}, R_{t}, \widetilde{M C}_{t}\right\}_{t=0}^{\infty}$ that satisfy equations (6) to (11) and equations (14) to (20), given $K_{0}^{Y}, K_{0}^{D}, \Pi_{0}$, and $R_{-1}$ and the sequence of monetary shocks $\left\{\varepsilon_{t}\right\}_{t=0}^{\infty}$. The variables that constitute the equilibrium are defined so as to ensure that their steady-state values remain constant over time. 


\subsection{Log-Linearizing the Model}

In order to examine how the economy responds to monetary policy shocks, I follow the method of King, Plosser, and Rebelo (1988), which involves using log-linear approximations to characterize fluctuations about a stationary steady-state equilibrium. The log-linearized first-order conditions are given in Appendix B.1.

The set of log-linearized equations can be reduced to a system of linear difference equations of the form:

$$
A E_{t} y_{t+1}=B y_{t}+C x_{t}
$$

where $y_{t}$ is a column vector containing the eight endogenous variables $\widehat{K}_{t+1}^{Y}, \widehat{K}_{t+1}^{D}, \widehat{\Pi}_{t+1}$, $\widehat{Y}_{t}, \widehat{K}_{t}^{Y}, \widehat{K}_{t}^{D}, \widehat{\Pi}_{t}$ and $\widehat{R}_{t-1}, x_{t}$ is a scalar containing the monetary policy shock $\varepsilon_{t}, A$ and $B$ are $8 \times 8$ matrices containing the coefficients on the endogenous variables in the model, and $C$ is an $8 \times 1$ matrix containing the reduced-form coefficients on the monetary policy shock. As shown by Blanchard and Kahn (1980), a unique stationary equilibrium exists when the number of stable eigenvalues possessed by the matrix $A^{-1} B$ is equal to the number of predetermined variables, which in this case is four.

\subsection{Calibrating the Model}

In calibrating the model I rely on three equilibrium relationships: The first-order conditions given by equations (6) and (10) imply that $\beta=\frac{\Pi^{*}}{R^{*}}$ and $\tilde{\rho}^{*}=\frac{1}{\beta}-(1-\delta)$, while zero profits in the long run implies that $\frac{y^{*}}{y^{*}+F C}=\frac{\theta-1}{\theta}$. I calibrate the theoretical model assuming a period to be one quarter.

Following King, Plosser, and Rebelo (1988), I assume a steady-state real rate of return on capital of 1.6 percent per quarter (which for a zero steady-state inflation rate $\left(\Pi^{*}\right)$ implies a gross quarterly nominal $\left(R^{*}\right)$ and real interest rate of 1.016 per quarter). For the depreciation rates of both market and household capital $\left(\delta=\delta_{Y}=\delta_{D}\right)$ I use Greenwood, Hercowitz, and Krussell's (1997) structures depreciation rate estimate of 0.0137 per quarter. I follow Greenwood, Rogerson, and Wright (1994) in assuming that $\frac{H^{Y *}}{H^{Y *}+H^{D *}}=\frac{3}{7}$ and $\frac{H^{D *}}{H^{Y *}+H^{D *}}=\frac{4}{7} \cdot{ }^{27} \mathrm{I}$ assume that the capital elasticity of output for both the householdproduced good $(\eta)$ and the market $\operatorname{good}(\alpha)$ is $0.3 .^{28} \mathrm{I}$ follow Yun (1996) and choose a steady-state elasticity of demand $(\theta)$ of 6 and follow Bernanke, Gertler, and Gilchrist (1999) in assuming that in any period only one-quarter of firms can reset their price (that

\footnotetext{
${ }^{27}$ These parameters are based on time-use survey data over the period 1971 to 1981.

${ }^{28}$ This differs slightly from the production function parameters assumed by Greenwood, Rogerson, and Wright (1994) who assume $\eta=0.32$ and $\alpha=0.29$. I choose to keep $\eta$ and $\alpha$ equal to each other in order to minimize asymmetries between the model's treatment of the two types of capital. Changing the assumed parameter values to those of Greenwood, et al. makes essentially no difference to the model's results.
} 
is, $\gamma=0.75)$ and that the intertemporal elasticity of labor supply $\left(s^{-1}\right)$ equals 3 . To obtain the value for both $J_{Y}^{-1^{\prime \prime}}\left(\delta_{Y}\right)$ and $J_{D}^{-1^{\prime \prime}}\left(\delta_{D}\right)$, I follow Kimball (1995) in assuming that $\frac{-\delta_{j} J_{j}^{\prime \prime}\left(\delta_{j}\right)}{J_{j}^{\prime}\left(\delta_{j}\right)}=0.2$ and therefore that $J_{j}^{\prime \prime}\left(\delta_{j}\right)=\frac{-0.2}{0.0137}$. Since by the inverse function theorem $J_{j}^{-1^{\prime}}\left(\delta_{j}\right)=\frac{1}{J_{j}^{\prime}\left(\delta_{j}\right)}=1, J_{j}^{-1^{\prime \prime}}\left(\delta_{j}\right)=-J_{j}^{\prime \prime}\left(\delta_{j}\right)=14.583$.

The form of the utility function and the household good production function implies that the utility elasticity parameters in the household's first-order conditions $\left(\rho_{x, y}\right.$ for $x, y=C^{Y}, H^{D}, K^{D}$, and $\left.\frac{M}{P}\right)$ are simple functions of $\eta, e, a$, and $\frac{C^{Y *}}{C^{D *}}$. Few econometric estimates exist as to the degree of substitution between household and market goods, so it was necessary to experiment with a range of values of the parameter $e$. I found little change in the impulse response functions implied by the model when $e$ was allowed to range from $-\frac{2}{3}$ to $\frac{2}{3}$. In the end I chose to assume unit elasticity of substitution $(e=0)$, since this simplified the values of a number of parameters in the model.

The parameters $a$ and $\frac{C^{Y *}}{C^{D *}}$ are functions of other parameters in the model, and are derived as follows. Equation (15) and the equilibrium value of $\widetilde{\rho}^{*}$ imply an equilibrium wage rate of $\widetilde{\omega}^{*}=(1-\alpha)\left(\frac{\alpha}{\widetilde{\rho}^{*}}\right)^{\frac{\alpha}{1-\alpha}}\left(\frac{\theta-1}{\theta}\right)^{\frac{1}{1-\alpha}}$, equations (8) to (11) imply that $\frac{K^{D *}}{H^{D *}}=$ $\frac{\eta}{1-\eta} \underset{\widetilde{\rho}^{*}}{\frac{\widetilde{\omega}^{*}}{\tilde{\rho}}}$, and (17) and (18) imply that $\frac{K^{Y *}}{H^{Y *}}=\frac{\alpha}{1-\alpha} \frac{\widetilde{\omega}^{*}}{\widetilde{\rho}^{*}}$. Together, these equilibrium conditions imply that $\frac{K^{Y *}}{K^{D *}}=\frac{1-\eta}{\eta} \frac{\alpha}{1-\alpha} \frac{H^{Y *}}{H^{D *}}$, which in turn allows me to calculate the parameters $c=$ $1-\frac{\delta \alpha}{\widetilde{\rho}^{*}}\left(1+\frac{\eta}{1-\eta} \frac{1-\alpha}{\alpha} \frac{H^{D^{*}}}{H^{Y *}}\right)$ and $i^{Y}=\frac{\delta \alpha}{\widetilde{\rho}^{*}}$ in the log-linearized market-clearing condition. The preceding equilibrium conditions are then used to calculate

$$
\frac{C^{Y *}}{C^{D *}}=c\left(\frac{K^{Y *}}{H^{Y *}}\right)^{\alpha}\left(\frac{K^{D *}}{H^{D *}}\right)^{-\eta} \frac{H^{Y *}}{H^{D *}} \frac{\theta-1}{\theta} .
$$

Equations (8) to (11) are also used to determine the parameter $a$, since these equations imply that:

$$
a=\left(\frac{\tilde{\rho}^{*}}{\eta}\left(\frac{K^{D *}}{H^{D *}}\right)^{1-\alpha}\left(\frac{C^{Y *}}{C^{D *}}\right)^{e-1}+1\right)^{-1}=\left(\frac{\widetilde{\omega}^{*}}{1-\eta}\left(\frac{H^{D *}}{K^{D *}}\right)^{\alpha}\left(\frac{C^{Y *}}{C^{D *}}\right)^{e-1}+1\right)^{-1}
$$

In parameterizing the monetary policy feedback rule, I follow both Kiley (1997) and Bernanke, Gertler, and Gilchrist (1999) in selecting values of $\phi_{Y}=0.125, \phi_{\Pi}=1.5$, and $\rho_{R}=0.9$.

\subsection{Response to a Monetary Shock}

The responses of the model's key variables to a 50 basis point increase in the annualized nominal interest rate are presented in figure 3 . The figure shows that output, consumption, (annualized) inflation, and both types of investment decline in response to the monetary 
shock. These responses conform to conventional wisdom as well as to the results of other calibrated theoretical models. The responses are, however, substantially stronger and more rapid than the responses observed empirically.

It can be seen from panels (h) and (i) of figure 3 that the responses of both types of investment to a monetary shock are quite similar in spite of the model's asymmetric treatment of market and household goods. ${ }^{29}$ In sections six and seven I assume that investment in the capital stocks used for market and household production involve different planning and completion times and consider how these rigidities can result in contrasting responses for the two categories of investment following a monetary policy shock. The fact that the benchmark model yields investment responses that are similar is therefore fortunate, since this allows me to interpret any differences in the augmented model's responses as being the result of differing project planning and completion times.

\section{Introduction of Time-to-Build, Time-to-Plan and Ex-post Investment Inflexibilities}

This section examines how time-to-build, time-to-plan, and ex-post investment inflexibilities can be added to the benchmark model. Time-to-build and time-to-plan become relevant when the investment required to bring about changes to the capital stock must take place over multiple periods. It therefore becomes necessary for the representative household to make its decision as to the optimal capital stock in advance. Ex-post investment inflexibilities are captured by requiring the household to commit to the amount of investment spending that it will undertake in each period of the multistage investment project. This investment plan, and therefore the realized capital stock, can be altered; however, any divergence from the initial plan entails some cost.

In this section I present a model which assumes that investment in the market capital stock takes place over two periods while investment in the household capital stock takes place over a single period. This is the simplest possible version of the model with timeto-build, time-to-plan, and ex-post investment inflexibilities; I present it in detail in order to give an idea of the modelling strategy involved and the basic nature of the problem. In section seven a more complicated and realistic version of this model will be outlined.

\footnotetext{
${ }^{29}$ Assuming that only the market good can be used for investment does not lead to any difference in the response of market and household investment. Stickiness in the price of the market good and full flexibility in the shadow price of the household good results in only a slightly larger response of market capital investment relative to household capital investment.
} 


\subsection{Setup of the Model}

I adapt Christiano and Eichenbaum's (1995) approach to modeling ex-post output inflexibilities in order to capture the inflexibilities that make it difficult to change an investment plan once it is underway. I assume that there is a non-linear function (specifically, a CES aggregator function) that relates the market investment spending that takes place over the two periods and the amount of market capital that obtains; this in turn is embedded in a standard cost-of-adjustment framework. The realized market capital stock is therefore given by:

$$
K_{t+2}^{Y}=\left(1-\delta_{Y}\right) K_{t+1}^{Y}+K_{t+1}^{Y} J\left(\frac{\phi^{Y}}{K_{t+1}^{Y}}\left(\sum_{i=1}^{2} \Psi_{i}^{Y}\left(I_{i, t+i-1}^{Y, t+i-1}\right)^{\sigma}\right)^{\frac{1}{\sigma}}\right)
$$

where

$$
\Psi_{i}^{Y}=\frac{\beta^{i-1}\left(I_{i}^{Y *}\right)^{1-\sigma}}{\sum_{j=1}^{2} \beta^{j-1}\left(I_{j}^{Y *}\right)^{1-\sigma}} \text { and } \phi^{Y}=\left(\frac{\sum_{i=1}^{2} \beta^{i-1}\left(I_{i}^{Y *}\right)^{1-\sigma}}{\sum_{i=1}^{2} \beta^{i-1}\left(I_{i}^{Y *}\right)}\right)^{\frac{1}{\sigma}} \sum_{i=1}^{2} I_{i}^{Y *}
$$

and where $-\infty<\sigma \leq 1$ and $I_{1}^{Y *}$ and $I_{2}^{Y *}$ are the steady-state levels of first- and secondperiod market investment spending. The superscript $t$ on the investment spending terms denotes the period in which the investment spending is planned. As in section five, equation (22) implies that the market capital stock in any period is known as of the preceding period.

Since market investment takes two periods to complete, the household necessarily begins to make its decisions about future market capital and the market investment plan two periods in advance. In deciding on how to spread its investment profile over the two periods, the household minimizes the expected discounted cost of market investment given a desired value for the $t+2$ capital stock. The household's problem in period $t$ is thus:

$\min _{\left\{I_{1, t}^{t}, I_{2, t+1}^{t}\right\}} P_{t} I_{1, t}^{Y}+R_{t}^{-1} P_{t+1} I_{2, t+1}^{Y}-R_{t}^{-1} E_{t}\left[R_{t+1}^{-1} P_{t+2}\right] K_{t+1}^{Y} J\left(\frac{\phi^{Y}}{K_{t+1}^{Y}}\left(\sum_{i=1}^{2} \Psi_{i}^{Y}\left(I_{i, t+i-1}^{Y, t}\right)^{\sigma}\right)^{\frac{1}{\sigma}}\right)$

subject to:

$$
J\left(\frac{\phi^{Y}}{K_{t+1}^{Y}}\left(\sum_{i=1}^{2} \Psi_{i}^{Y}\left(I_{i, t+i-1}^{Y, t+i-1}\right)^{\sigma}\right)^{\frac{1}{\sigma}}\right) \geq \frac{E_{t} K_{t+2}^{Y}}{K_{t+1}^{Y}}-\left(1-\delta_{Y}\right)
$$

where $E_{t} K_{t+2}$ is yet to be determined. The market investment cost-minimization problem yields the following optimal investment plan: 


$$
\begin{gathered}
I_{1, t}^{Y, t}=\left(\frac{I_{1}^{Y *}}{I_{1}^{Y *}+I_{2}^{Y *}}\right)\left(\frac{I_{1}^{Y *}+I_{2}^{Y *} \beta}{I_{1}^{Y *}+I_{2}^{Y *}(\beta)^{\frac{1}{1-\sigma}}\left(\frac{\Pi_{t+1}}{R t}\right)^{\frac{-\sigma}{1-\sigma}}}\right)^{\frac{1}{\sigma}} K_{t+1}^{Y} E_{t}\left[J^{-1}\left(\frac{K_{t+2}^{Y}}{K_{t+1}^{Y}}-\left(1-\delta_{Y}\right)\right)\right] \\
I_{2, t+1}^{Y, t}=\left(\frac{I_{2}^{Y *}}{I_{1}^{Y *}}\right)(\beta)^{\frac{1}{1-\sigma}}\left(\frac{\Pi_{t+1}}{R_{t}}\right)^{\frac{-1}{1-\sigma}} I_{1, t}^{Y, t} .
\end{gathered}
$$

Given the distribution of market investment over the two periods, the household then chooses its desired period $t+2$ capital stock. The model is solved in the same way as in the benchmark case, with household utility (equation (1)) maximized under the household's budget constraint, now defined as:

$$
B_{t}+M_{t} \leq R_{t-1} B_{t-1}+M_{t-1}+\omega_{t} H_{t}^{Y}+\rho_{t} K_{t}^{Y}+\text { profits }{ }_{t}-T_{t}-P_{t} C_{t}^{Y}-P_{t} I_{1, t}^{Y, t}-P_{t} I_{2, t}^{Y, t}-P_{t} I_{t}^{D}
$$

and the evolution of the two types of capital, defined in equations (23) and (5).

The household's first-order conditions with respect to its choice of $C_{t}^{Y}, \frac{M_{t}}{P_{t}}, H_{t}^{Y}, H_{t}^{D}$, and $K_{t+1}^{D}$ are identical to the benchmark case while the household's first-order condition with respect to its choice of $E_{t} K_{t+2}^{Y}$ is now:

$$
\begin{aligned}
& \frac{-1}{1+\frac{I_{2}^{Y *}}{I_{1}^{Y *}}} \frac{1+\frac{I_{2}^{Y *}}{I_{1}^{Y *}} \beta}{1+\frac{I_{2}^{Y *}}{I_{1}^{Y *}} \beta^{\frac{1}{1-\sigma}}\left(\frac{\Pi_{t+1}}{R_{t}}\right)^{\frac{-\sigma}{1-\sigma}}}\left(\frac{R_{t}}{\Pi_{t+1}}+\frac{I_{2}^{Y *}}{I_{1}^{Y *}} \beta^{\frac{1}{1-\sigma}}\left(\frac{R_{t}}{\Pi_{t+1}}\right)^{\frac{1}{1-\sigma}}\right) \\
& \times E_{t}\left[\frac{R_{t+1}}{\Pi_{t+2}} J^{-1^{\prime}}\left(\frac{K_{t+2}^{Y}}{K_{t+1}^{Y}}-\left(1-\delta_{Y}\right)\right)\right]+E_{t}\left[\widetilde{\rho}_{t+2}\right] \\
& =\left(\frac{1}{1+\frac{I_{2}^{Y *}}{I_{1}^{Y *}}}\right)\left(1+\frac{I_{2}^{Y *}}{I_{1}^{Y *}} \beta\right)^{\frac{1}{\sigma}} \\
& \times E_{t}\left[\frac{\left(\frac{R_{t+1}}{\Pi_{t+2}}+\frac{I_{2}^{Y *}}{I_{1}^{Y *}} \beta^{\frac{1}{1-\sigma}}\left(\frac{R_{t+1}}{\Pi_{t+2}}\right)^{\frac{1}{1-\sigma}}\right)}{\left(1+\frac{I_{2}^{Y *}}{I_{1}^{Y *}} \beta^{\frac{1}{1-\sigma}}\left(\frac{\Pi_{t+2}}{R_{t+1}}\right)^{\frac{-\sigma}{1-\sigma}}\right)^{\frac{1}{\sigma}}} J^{-1}\left(\frac{K_{t+3}^{Y}}{K_{t+2}^{Y}}-\left(1-\delta_{Y}\right)\right)\right] \\
& -\left(\frac{1}{1+\frac{I_{2}^{Y *}}{I_{1}^{Y *}}}\right)\left(1+\frac{I_{2}^{Y *}}{I_{1}^{Y *}} \beta\right)^{\frac{1}{\sigma}}
\end{aligned}
$$




$$
\times E_{t}\left[\frac{\left(\frac{R_{t+1}}{\Pi_{t+2}}+\frac{I_{2}^{Y *}}{I_{1}^{Y *}} \beta^{\frac{1}{1-\sigma}}\left(\frac{R_{t+1}}{\Pi_{t+2}}\right)^{\frac{1}{1-\sigma}}\right)}{\left(1+\frac{I_{2}^{Y *}}{I_{1}^{Y *}} \beta^{\frac{1}{1-\sigma}}\left(\frac{\Pi_{t+2}}{R_{t+1}}\right)^{\frac{-\sigma}{1-\sigma}}\right)^{\frac{1}{\sigma}}} J^{-1^{\prime}}\left(\frac{K_{t+3}^{Y}}{K_{t+2}^{Y}}-\left(1-\delta_{Y}\right)\right)\left(\frac{K_{t+3}^{Y}}{K_{t+2}^{Y}}\right)\right]
$$

In period $t$ the household also has the opportunity to revise its period $t-1$ market investment plan for market capital that is set to come on-line in period $t+1$. While a revised plan may yield a preferred level for the final market capital stock, the revision requires the household to incur a cost. (This cost is captured by the assumed form of the aggregator function.) Second-stage market investment planned and undertaken in period $t$ is defined as:

$$
\begin{aligned}
I_{2, t}^{Y, t}= & \left(\left(1+\frac{I_{2}^{Y *}}{I_{1}^{Y *}} \beta\right)\left(\frac{1}{1+\frac{I_{2}^{Y *}}{I_{1}^{Y *}}} K_{t}^{Y} J^{-1}\left(\frac{K_{t+1}^{Y}}{K_{t}^{Y}}-\left(1-\delta_{Y}\right)\right)\right)^{\sigma}-\left(I_{1, t-1}^{Y, t-1}\right)^{\sigma}\right)^{\frac{1}{\sigma}} \\
& \times\left(\left(\frac{I_{2}^{Y *}}{I_{1}^{Y *}}\right)^{1-\sigma} \beta\right)^{\frac{-1}{\sigma}} .
\end{aligned}
$$

Given $I_{2, t}^{t}$, the household chooses its desired period $t+1$ capital stock. The household's first-order condition with respect to its choice of $K_{t+1}^{Y}$ is now:

$$
\begin{aligned}
& -\left(\frac{1}{1+\frac{I_{2}^{Y *}}{I_{1}^{Y *}}}\right)^{\sigma}\left(\frac{I_{2, t}^{Y, t}}{K_{t}^{Y} J^{-1}\left(\frac{K_{t+1}^{Y}}{K_{t}^{Y}}-\left(1-\delta_{Y}\right)\right)}\right)^{1-\sigma}\left(\frac{1+\frac{I_{2}^{Y *}}{I_{1}^{Y *}} \beta}{\left(\frac{I_{2}^{Y *}}{I_{1}^{Y *}}\right)^{1-\sigma} \beta}\right) \\
& \times\left(\frac{R_{t}}{E_{t} \Pi_{t+1}}\right) J^{-1^{\prime}}\left(\frac{K_{t+1}^{Y}}{K_{t}^{Y}}-\left(1-\delta_{Y}\right)\right)+E_{t}\left[\widetilde{\rho}_{t+1}\right] \\
= & \left(\frac{1}{1+\frac{I_{2}^{Y *}}{I_{1}^{Y *}}}\right)\left(1+\frac{I_{2}^{Y *}}{I_{1}^{Y *}} \beta\right)^{\frac{1}{\sigma}} \frac{\left(\left(\frac{R_{t}}{\Pi_{t+1}}\right)+\frac{I_{2}^{Y *}}{I_{1}^{Y *}} \beta^{\frac{1}{1-\sigma}}\left(\frac{R_{t}}{\Pi_{t+1}}\right)^{\frac{1}{1-\sigma}}\right)}{\left(1+\frac{I_{2}^{Y *}}{I_{1}^{Y *}} \beta^{\frac{1}{1-\sigma}}\left(\frac{\Pi_{t+1}}{R_{t}}\right)^{\frac{-\sigma}{1-\sigma}}\right)^{\frac{1}{\sigma}}} \\
& \times E_{t}\left[J^{-1}\left(\frac{K_{t+2}^{Y}}{K_{t+1}^{Y}}-\left(1-\delta_{Y}\right)\right)-J^{-1^{\prime}}\left(\frac{K_{t+2}^{Y}}{K_{t+1}^{Y}}-\left(1-\delta_{Y}\right)\right)\left(\frac{K_{t+2}^{Y}}{K_{t+1}^{Y}}\right)\right] .
\end{aligned}
$$

The household's first-order conditions are given by equations (6) to (9), (11), (26), and (28). All other first-order conditions, as well as the monetary policy rule, remain unchanged 
with the introduction of time-to-build and ex-post investment inflexibilities. The economy's market-clearing condition changes slightly, to:

$$
C_{t}^{Y}+I_{1, t}^{Y, t}+I_{2, t}^{Y, t}+I_{t}^{D}=Y_{t}
$$

\subsection{Equilibrium}

Equilibrium is an allocation $\left\{C_{t}^{Y}, \frac{M_{t}}{P_{t}}, H_{t}^{Y}, H_{t}^{D}, K_{t+1}^{Y}, E_{t} K_{t+2}^{Y}, K_{t+1}^{D}, Y_{t}\right\}_{t=0}^{\infty}$ and a sequence of values $\left\{\Pi_{t+1}, \widetilde{\omega}_{t}, \tilde{\rho}_{t}, R_{t}, \widetilde{M C}\right\}_{t=0}^{\infty}$ that satisfy equations (6) to (9), (11), (26), (28), (14) to (12), and (29), given $K_{0}^{Y}, K_{0}^{D}, \Pi_{0}, R_{-1}$, and $I_{1,-1}^{Y,-1}$ and the sequence of monetary shocks $\left\{\varepsilon_{t}\right\}_{t=0}^{\infty}$.

\subsection{Log-linearizing the Model}

As with the benchmark model, the model's first-order conditions can be log-linearized and solved as a system of linear difference equations. (The new log-linearized first-order conditions are given in Appendix B.2.) The set of log-linearized equations can be reduced to a system of ten linear difference equations and written in a form similar to equation (21). In this case, $y_{t}$ is a column vector containing $E_{t} \widehat{K}_{t+2}^{Y}, \widehat{K}_{t+1}^{Y}, \widehat{K}_{t+1}^{D}, \widehat{\Pi}_{t+1}, \widehat{Y}_{t}, \widehat{K}_{t}^{Y}, \widehat{K}_{t}^{D}, \widehat{\Pi}_{t}$, $\widehat{R}_{t-1}$, and $\widehat{I}_{1, t-1}^{Y, t-1}$, and a unique stationary equilibrium exists if the matrix $A^{-1} B$ has five stable eigenvalues.

\subsection{Calibrating the Model}

The model with time-to-build and ex-post investment inflexibilities contains two additional parameters: $\sigma$, the CES aggregator parameter, and $\left(\frac{I_{2}^{Y *}}{I_{1}^{Y *}}\right)$, the ratio of second- to firstperiod market investment spending in the steady-state equilibrium. The parameter $\sigma$ can take on values ranging from $-\infty$ to 1 depending on the degree of substitution between $I_{1, t}^{Y}$ and $I_{2, t+1}^{Y}$. I therefore considered a number of different values of $\sigma$; the corresponding responses are presented and discussed in the following section. The ratio $\left(\frac{I_{2}^{Y *}}{I_{1}^{Y *}}\right)$ can take on values ranging from 0 to $\infty$ depending on what one wishes to assume about the equilibrium division of market investment spending over the two periods. In the following simulations I assume that investment spending in the steady state is evenly split over the two periods, that is, $\left(\frac{I_{2}^{Y *}}{I_{1}^{Y *}}\right)=1$. The assumption that $I_{1}^{Y *}=I_{2}^{Y *}$ simplifies many of the equations of the two-period case and could have been assumed at the beginning of the section to allow a much simpler exposition of the model. The advantage, however, of deriving the model with $I_{1}^{Y *} \neq I_{2}^{Y *}$ is that it provides a convenient way to describe time-to-plan. Specifically, the two-period time-to-build model derived in this section can be easily converted into a 
model involving one-period time-to-plan and one period time-to-build by simply letting the parameter $\left(\frac{I_{2}^{Y *}}{I_{1}^{Y *}}\right)$ approach $\infty$. This method of capturing time-to-plan, used also by Christiano and Todd (1996), is employed in deriving the fully specified model of section eight.

Note from equations (26) and (28) that the equilibrium value of the capital rental rate is now $\left(1+\beta\left(\frac{I_{2}^{Y *}}{I_{1}^{Y *}}\right)\right)\left[\beta\left(1+\left(\frac{I_{2}^{Y *}}{I_{1}^{Y *}}\right)\right)\right]^{-1}\left(\frac{1}{\beta}+\delta_{Y}-1\right)$, as compared to $\left(\frac{1}{\beta}+\delta_{Y}-1\right)$. The new capital rental rate implies that $\frac{K^{D *}}{H^{D *}}=\frac{\eta}{1-\eta}\left(1+\beta\left(\frac{I_{2}^{Y *}}{I_{1}^{Y *}}\right)\right)\left[\beta\left(1+\left(\frac{I_{2}^{Y *}}{I_{1}^{Y *}}\right)\right)\right]^{-1} \frac{\widetilde{\omega}^{*}}{\widetilde{\rho}^{*}}$ and $\frac{K^{Y *}}{K^{D *}}=\frac{1-\eta}{\eta} \frac{\alpha}{1-\alpha}\left(1+\beta\left(\frac{I_{2}^{Y *}}{I_{1}^{Y *}}\right)\right)\left[\beta\left(1+\left(\frac{I_{2}^{Y *}}{I_{1}^{Y *}}\right)\right)\right]^{-1} \frac{H^{Y *}}{H^{D *}}$ in equilibrium.

\subsection{Response to a Monetary Shock}

The introduction of time-to-build and ex-post investment inflexibilities leaves the responses of most of the key variables largely unchanged. The only noticeable difference involves the responses of the market good's capital stock and investment. Figure 4 reports the response of market investment to a monetary shock in the augmented model for a range of values of $\sigma$. To allow easy comparison, the response of market investment in the benchmark case has also been plotted.

For values of $\sigma$ that imply little substitutability between investment spending in the two periods ( $\sigma$ more negative), there is a delay in the response of investment to changes in monetary policy. For these impulse response functions the monetary shock has its maximum effect on investment in the period immediately following the shock, in contrast to the benchmark model in which investment's maximum response occurs in the period of the shock.

The results are quite intuitive. The tightening of monetary policy affects market investment projects differently depending on whether a project is underway or yet to begin. The response of market investment projects that one already underway is muted because any change in investment plans involves a substantial cost. However, the response of market investment projects that are yet to begin is unhindered by previous plans. In the period of the shock, approximately half of the projects in market investment are already underway, but in the subsequent period all of the projects being undertaken were begun after the shock. As a result, the response of market investment is stronger in the period following the shock. Market investment in all subsequent periods is also unhindered by previous investment plans, and returns slowly to its steady-state level after having peaked in the first period after the shock.

Figure 4 also demonstrates how the magnitude of the initial response of market investment varies with the elasticity of substitution between investment spending over the two 
periods. A lower degree of substitution (a more negative value of $\sigma$ ) implies greater ex-post investment inflexibilities, a greater cost of changing an investment plan, and a more timid initial response to a change in monetary policy.

Figure 5 compares how investment in the two types of capital responds to a monetary policy shock for various values of $\sigma$. The results show that, when investment in the market good's capital stock involves time-to-build and ex-post investment inflexibilities, its response to a monetary policy shock is smaller and slower than the response of household investment (which remains invariant to the different values of $\sigma$ ). This result brings the theoretical model closer to the empirical results discussed in section three. Figure 6 compares the response of market capital investment and starts to a monetary shock for various values of $\sigma$. The figure shows that in the model with time-to-build and ex-post investment inflexibilities building starts for market capital (also invariant to different values of $\sigma$ ) respond more rapidly than investment to changes in monetary policy. Figure 7 plots market capital starts together with starts for household capital. (The response of starts is again invariant to the different values of $\sigma$ ). Starts for market capital respond less strongly than starts for household capital, again moving the model's predictions closer to what is actually observed in the data. Taken together, these results suggest that a sticky-price monetary-businesscycle model with time-to-build, ex-post investment inflexibilities, and adjustment costs is capable of producing responses of investment and starts to monetary policy shocks that are closer to those found empirically.

\section{The Fully-Specified Model with Time-to-Build, Time-to- Plan, and Ex-post Investment Inflexibilities}

The simple model of the previous section was presented in order to explain the method by which time-to-build, time-to-plan, and ex-post investment inflexibilities can be introduced into the model. In this section I present results from a model in which the assumed project planning and completion times are matched with observed estimates.

Based on a study of project completion patterns in 1991, the U.S. Bureau of the Census (1992) estimated that the average project completion time for private structures building projects is 14 months. Maffertone's (1998) discussion of the stages through which a building project progresses from its initial conception to the commencement of construction suggests planning times of at least six months, if not more. ${ }^{30}$ I therefore assume four-period time-

\footnotetext{
${ }^{30}$ According to Maffertone (1998, p.38), a project passes through a number of planning stages before any construction begins. In the pre-planning stage the project is proposed. Once accepted the project goes through the planning stage, during which time an architect is selected and designs are developed. The project then enters a contract-bidding stage followed by a period of negotiations which ends in the contract's being awarded to the successful party. It is only after this that construction of the project begins.
} 
to-build and two-period time-to-plan for market investment.

The March release of the Bureau of the Census' Survey of Housing Starts contains a supplement in which project completion times for private residential buildings are reported. Over the last 10 years the time involved in building the average residential building has been a little over six and-a-half months; I therefore calibrate two-period time-to-build for household investment. In a further supplement to the March release of the Survey of Housing Starts the length of time between when a building permit issued is and when construction begins is reported to average about one month. However, since time-to-plan involves more than just the time between the permit's issue and the building's start, I assume one-period time-to-plan for household investment.

The model is exactly the same as in the preceding section except for modifications to the capital evolution equations (previously (22) and (5)), which now reflect the six periods involved in market capital investment (two for planning and four for building):

$$
K_{t+6}^{Y}=\left(1-\delta_{Y}\right) K_{t+5}^{Y}+K_{t+5}^{Y} J\left(\frac{\phi^{Y}}{K_{t+5}^{Y}}\left(\sum_{i=1}^{6} \Psi_{i}^{Y}\left(I_{i, t+i-1}^{Y, t+i-1}\right)^{\sigma}\right)^{\frac{1}{\sigma}}\right)
$$

where

$$
\Psi_{i}^{Y}=\frac{\beta^{i-1}\left(I_{i}^{Y *}\right)^{1-\sigma}}{\sum_{j=1}^{6} \beta^{j-1}\left(I_{j}^{Y *}\right)^{1-\sigma}}, \text { and } \phi^{Y}=\left(\frac{\sum_{i=1}^{6} \beta^{i-1}\left(I_{i}^{Y *}\right)^{1-\sigma}}{\sum_{i=1}^{6} \beta^{i-1}\left(I_{i}^{Y *}\right)}\right)^{\frac{1}{\sigma}} \sum_{i=1}^{6} I_{i}^{Y *}
$$

as well as the three periods involved in household capital investment (one for planning and two for building): ${ }^{31}$

$$
K_{t+3}^{D}=\left(1-\delta_{Y}\right) K_{t+2}^{D}+K_{t+2}^{D} J\left(\frac{\phi^{D}}{K_{t+2}^{D}}\left(\sum_{i=1}^{3} \Psi_{i}^{D}\left(I_{i, t+i-1}^{D, t+i-1}\right)^{\sigma}\right)^{\frac{1}{\sigma}}\right)
$$

where

$$
\Psi_{i}^{D}=\frac{\beta^{i-1}\left(I_{i}^{D *}\right)^{1-\sigma}}{\sum_{j=1}^{3} \beta^{j-1}\left(I_{j}^{D *}\right)^{1-\sigma}} \text {, and } \phi^{D}=\left(\frac{\sum_{i=1}^{3} \beta^{i-1}\left(I_{i}^{D *}\right)^{1-\sigma}}{\sum_{i=1}^{3} \beta^{i-1}\left(I_{i}^{D *}\right)}\right)^{\frac{1}{\sigma}} \sum_{i=1}^{3} I_{i}^{D *}
$$

\footnotetext{
${ }^{31}$ The assumption that project planning and completion times remain constant over the business cycle is justified on several grounds. Kydland and Prescott (1982, p.1349) argue that they find "...no evidence that capital goods are built significantly more rapidly when total investment activity is higher or lower." I also find evidence indicating little variance in residential and structures building project completion times. The time series of housing project completion times contained in the March release of the Survey of Housing Starts varies only slightly over the last business cycle. Similarly, Montgomery (1995, 1996) reports little variability in structures building project completion times over the period 1961-1991.
} 
In any period $t$ the household chooses the utility-maximizing levels of $\left\{E_{t} K_{t+j}^{Y}\right\}_{j=2}^{6}$, $K_{t+1}^{Y},\left\{E_{t} K_{t+j}^{D}\right\}_{j=2}^{3}$, and $K_{t+1}^{D}$, given the cost-minimizing investment spending profiles associated with the desired levels of the of the capital stock, namely $\left\{I_{i, t+i-1}^{Y, t}\right\}_{i=1}^{6},\left\{I_{i, t+i-2}^{Y, t}\right\}_{i=2}^{6}$, $\left\{I_{i, t+i-3}^{Y, t}\right\}_{i=3}^{6},\left\{I_{i, t+i-4}^{Y, t}\right\}_{i=4}^{6},\left\{I_{i, t+i-5}^{Y, t}\right\}_{i=5}^{6},\left\{I_{i, t+i-6}^{Y, t}\right\}_{i=6}^{6},\left\{I_{i, t+i-1}^{D, t}\right\}_{i=1}^{3},\left\{I_{i, t+i-2}^{D, t}\right\}_{i=2}^{3}$, and $\left\{I_{i, t+i-3}^{D, t}\right\}_{i=3}^{3}$, respectively. The eight first-order conditions that obtain from this problem replace equations (11), (26), and (28) of the previous model.

Equilibrium is an allocation $\left\{C_{t}^{Y}, \frac{M_{t}}{P_{t}}, H_{t}^{Y}, H_{t}^{D}, K_{t+1}^{Y}, E_{t} K_{t+2}^{Y}, E_{t} K_{t+3}^{Y}, E_{t} K_{t+4}^{Y}, E_{t} K_{t+5}^{Y}\right.$, $\left.E_{t} K_{t+6}^{Y}, K_{t+1}^{D}, E_{t} K_{t+2}^{D}, E_{t} K_{t+3}^{D}, Y_{t}\right\}_{t=0}^{\infty}$ and a sequence of values $\left\{\Pi_{t+1}, \widetilde{\omega}_{t}, \widetilde{\rho}_{t}, R_{t}, \widetilde{M C}_{t}\right\}_{t=0}^{\infty}$ that satisfy equations (6) to (9), the eight first-order conditions for the market and household capital stocks, equations (14) to (12), and the new market-clearing condition of:

$$
C_{t}^{Y}+\sum_{i=1}^{6} I_{i, t}^{Y, t}+\sum_{i=1}^{3} I_{i, t}^{D, t}=Y_{t} .
$$

The solution takes $K_{0}^{Y}, K_{0}^{D}, \Pi_{0}, R_{-1},\left\{I_{i,-1}^{Y,-1}\right\}_{i=1}^{5},\left\{I_{i,-1}^{D,-1}\right\}_{i=1}^{2},\left\{I_{i,-2}^{Y,-2}\right\}_{i=1}^{4},\left\{I_{i,-2}^{D,-2}\right\}_{i=1}^{1}$, $\left\{I_{i,-3}^{Y,-3}\right\}_{i=1}^{3},\left\{I_{i,-4}^{Y,-4}\right\}_{i=1}^{2},\left\{I_{i,-5}^{Y,-5}\right\}_{i=1}^{1}$, and the sequence of monetary shocks $\left\{\varepsilon_{t}\right\}_{t=0}^{\infty}$ as given.

As with the previous models the first-order conditions are log-linearized and reduced to a set of 32 linear equations that can be written in a form similar to equation (21). In this case, $y_{t}$ is a column vector containing $E_{t} \widehat{K}_{t+6}^{Y}, E_{t} \widehat{K}_{t+5}^{Y}, E_{t} \widehat{K}_{t+4}^{Y}, E_{t} \widehat{K}_{t+3}^{Y}, E_{t} \widehat{K}_{t+3}^{D}, E_{t} \widehat{K}_{t+2}^{Y}$, $E_{t} \widehat{K}_{t+2}^{D}, \widehat{K}_{t+1}^{Y}, \widehat{K}_{t+1}^{D}, \widehat{\Pi}_{t+1}, \widehat{Y}_{t}, \widehat{K}_{t}^{Y}, \widehat{K}_{t}^{D}, \widehat{\Pi}_{t}, \widehat{R}_{t-1}, \widehat{I}_{5, t-1}^{Y, t-1}, \widehat{I}_{4, t-1}^{Y, t-1}, \widehat{I}_{3, t-1}^{Y, t-1}, \widehat{I}_{2, t-1}^{Y, t-1}, \widehat{I}_{1, t-1}^{Y, t-1}$, $\widehat{I}_{2, t-1}^{D, t-1}, \widehat{I}_{1, t-1}^{D, t-1}, \widehat{I}_{4, t-2}^{Y, t-2}, \widehat{I}_{3, t-2}^{Y, t-2}, \widehat{I}_{2, t-2}^{Y, t-2}, \widehat{I}_{1, t-2}^{Y, t-2}, \widehat{I}_{1, t-2}^{Y, t-2}, \widehat{I}_{3, t-3}^{Y, t-3}, \widehat{I}_{2, t-3}^{Y, t-3}, \widehat{I}_{1, t-3}^{Y, t-3}, \widehat{I}_{2, t-4}^{Y, t-4}, \widehat{I}_{1, t-4}^{Y, t-4}$ and $\widehat{I}_{1, t-5}^{Y, t-5}$. A unique stationary equilibrium exists when the matrix $A^{-1} B$ has 22 stable eigenvalues.

I assume that in the steady-state equilibrium the expenditure involved in planning a market capital investment project is evenly split over the two planning periods, while the expenditure involved in construction is evenly split over the four building periods. In terms of calibrating the model this implies that $\left(\frac{I_{2}^{Y *}}{I_{1}^{Y *}}\right)=1$ and $\left(\frac{I_{4}^{Y *}}{I_{3}^{Y *}}\right)=\left(\frac{I_{5}^{Y *}}{I_{4}^{Y *}}\right)=\left(\frac{I_{6}^{Y *}}{I_{5}^{Y *}}\right)=$ 1. Since the first two periods are planning stages that involve relatively small levels of expenditure, I assume $\left(\frac{I_{3}^{Y *}}{I_{2}^{Y *}}\right)=10,000$. Similarly, I assume that household construction is evenly split over the two building periods in the steady-state equation, and calibrate the model assuming $\left(\frac{I_{2}^{D *}}{I_{1}^{D *}}\right)=10,000$ and $\left(\frac{I_{3}^{D *}}{I_{2}^{D *}}\right)=1$. To capture the notion that it is very costly to begin a project without having gone through the necessary planning stages, I assume a very low degree of substitutability between investment spending in the various periods, and set $\sigma=-50,000$. 
The impulse response functions for market (structures) and household (residential) investment and starts are presented in figures 8 to 11. It is evident that this version of the model generates responses of starts and investment that are qualitatively similar to their empirical counterparts. Direct comparisons of the predicted responses from the model and the empirical responses from the VARs of section four (figures 12 to 15) indicate that in most cases the calibrated model appears to do well in replicating the empirically observed responses.

\section{Comparison of the Theoretical and Empirical Results}

I now compare the augmented model's predicted responses for residential and structures investment to the observed responses from the VARs. ${ }^{32}$ This comparison ignores the model's predictions for such key variables as overall output and the price level; while this focus is reasonable given that my principal interest is in capturing investment behavior, it is also necessary inasmuch as the model has less success in explaining these other variables. ${ }^{33}$ Given that the theoretical model is most likely "wrong" in these important respects, it seems pointless to try to evaluate how well the entire model performs. Instead, a more fruitful exercise involves considering to what degree introducing time-to-build, time-to-plan, and ex-post investment inflexibilities can yield responses of value put in place and starts that more closely match the data. ${ }^{34}$

Of course, the responses of value put in place and starts from the augmented model are not invariant to the model's other assumptions, of which at least some are suspected to be "wrong." Therefore, some caution is warranted when comparing the impulse response functions from the theoretical model with those observed in the data since it is not immediately obvious whether these incorrect assumptions are partly driving my results. However, since the responses from the benchmark model are also contaminated by these incorrect assumptions, it is probably legitimate to ascribe the improvement in fit between the bench-

\footnotetext{
${ }^{32}$ Market and household capital in the theoretical model correspond to structures and residential capital, respectively. Henceforth, market capital will be referred to as structures capital while household capital will be referred to as residential capital. I also use the term "value put in place" when referring to investment in the theoretical model, which corresponds to the terminology used for the VAR systems.

${ }^{33}$ The theoretical model generates a response for inflation that is largest over the quarters immediately following the shock, a result that conflicts dramatically with the VARs, which yield a very slow response of prices and inflation. The theoretical model yields a maximum response of output that is about twice as large as the VAR responses and that occurs substantially sooner. Despite this, however, the inclusion of time-to-build/plan in investment in the model noticeably improves the empirical fit of output's response relative to the benchmark model.

${ }^{34}$ Given that I wish to avoid evaluating the entire theoretical model, I also choose not to use other methods for model assessment (such as moment and spectra matching) that are often employed in the calibrated business cycle literature.
} 
mark and augmented models to my incorporating time-to-build, time-to-plan, and ex-post investment inflexibilities into the model.

\subsection{Qualitative Comparisons of the Theoretical and Empirical Results}

A comparison of the theoretical and VAR responses can be made visually simply by combining figures 8 to 11 (which give the responses of residential and structures starts and value put in place from the augmented model) with figure 2 (which presents the corresponding results from the VAR systems). It is clear from even a casual inspection that the augmented model is better able to replicate the differential timings and magnitudes of the observed responses of residential and structures starts and value put in place to a monetary policy shock.

Figures 12 to 15 plot the responses of residential and structures starts and value put in place that obtain from the benchmark model, augmented model, and the VAR models; also shown are the standard error bands associated with the VAR responses. It is evident from these figures that the augmented model also has greater success in replicating the actual timings and magnitudes of the responses than the benchmark model. The degree to which the augmented model better matches the data is, however, somewhat sensitive to the method of monetary policy identification assumed; for the Federal funds rate methods of identification the augmented model displays a very clear and noticeable improvement, but the improvement is less dramatic for the nonborrowed reserves systems. I also note that in most cases the responses of residential and structures starts and value put in place generated by the augmented model are slightly smaller than their empirical counterparts - although this finding can be easily rectified by assuming a smaller calibrated value for the cost-ofadjustment parameter. One reasonable interpretation of this result is that the calibrated value of the adjustment cost parameter - which is based on reduced-form model estimatesdoes not disentangle the separate effects of time-to-build/time-to-plan and adjustment costs, and is therefore too high. ${ }^{35}$

\subsection{Formal Comparisons of the Theoretical and Empirical Results}

Cogley and Nason (1994) have suggested a formal methodology for calculating the distance between the empirical and theoretical impulse response functions of a given variable. Their procedure involves constructing a statistic that resembles a quasi-LM test statistic, namely:

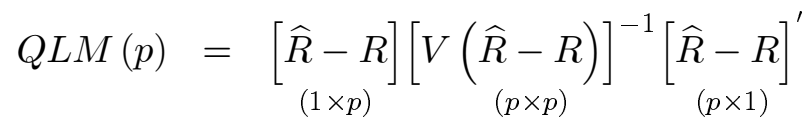

\footnotetext{
${ }^{35}$ Kimball (1995) takes his calibrated value of the cost-of-adjustment parameter from estimates by Cummins, Hasset and Hubbard (1994) and Shapiro (1986).
} 


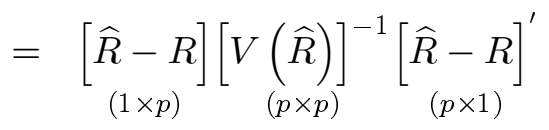

where

$\widehat{R}=$ the vector of responses from the VAR model;

$R=$ the vector of responses from the theoretical model;

$V(\widehat{R}-R)=V(\widehat{R})=$ the variance-covariance matrix of $(\widehat{R}-R)$; and,

$p=$ the number of periods over which the impulse response functions are computed (in this case, 9$).{ }^{36}$

This statistic was calculated for the responses of residential and structures value put in place and starts from the benchmark, augmented, and VAR models; the results are presented in table 3. The responses from the augmented model are closer in distance to those observed empirically in all but one case. ${ }^{37}$

\section{Conclusion}

The empirical and theoretical results of this paper provide support for the hypothesis that differential project planning and completion times can explain the contrasting responses of residential and structures investment to changes in monetary policy. In line with the predictions of the hypothesis, the empirical results find that structures and residential starts respond to changes in monetary policy more strongly and more rapidly than the corresponding components of investment, and also that the response of structures starts is slower and weaker than the response of residential starts. The lack of any noticeable contrast between the difference in structures starts and investment and the difference in residential starts and investment, which runs counter to the predictions of the paper's hypothesis, is accounted for by the continuation of large building projects in the form of multifamily homes.

The theoretical portion of the paper finds that a sticky-price monetary business cycle model involving two types of capital with different project planning and completion times is able to produce responses to monetary policy innovations that are very similar to those observed empirically.

\footnotetext{
${ }^{36}$ Like the standard error bands for the impulse response functions, the variance-covariance matrix of $\widehat{R}$ is also calculated using a Bayesian Monte Carlo method.

${ }^{37}$ The quadratic distance measures from table 3 can also be interpreted as indicating whether the model's responses lie in a region of high probability given the results of the VAR model.

A related exercise involves subjecting the benchmark and augmented theoretical models to a sequence of monetary shocks that generate responses of nominal interest rates from the theoretical models that are exactly equal to those emerging from the VAR system. The responses of structures and residential starts and value put in place implied by these shocks are then used as the vector of responses from the theoretical model when constructing the Cogley and Nason distance measure. The resulting measurements (not shown) also find the responses from the augmented model to be closer to those observed empirically.
} 
A comparison of the paper's empirical and theoretical results seems to imply that in a monetary business cycle model augmented with realistic project planning and completion times the observed responses of residential and structures investment to monetary shocks are consistent with monetary policy's working entirely through the IS/LM channel. This appears to suggest little need to appeal to the "bank-lending channel" to explain the contrasting responses of residential and structures investment. I am cautious, however, in making such a conclusion: The theoretical model developed in this paper concentrates on only one aspect of the transmission of monetary policy, and as a result does not perform as well in replicating the observed responses of other key variables in the model, even when it does well in reproducing the observed responses of residential and structures investment and starts. ${ }^{38}$ The model, therefore, cannot be regarded as providing a complete explanation of the transmission of monetary policy and should not be used to evaluate the relative importance of the various channels of monetary policy transmission.

The paper's empirical and theoretical results can, nonetheless, be regarded as providing evidence in support of the hypothesis that long project planning and completion times account for the slow response of structures investment following a monetary tightening. The finding has clear policy implications for central bankers. If central bankers are trying to reduce demand by tightening monetary policy, yet find that structures investment fails to respond, they should realize that this is in part due to the continuation of large multiperiod building projects. Central bankers should perhaps also use structures building starts, rather than investment, in gauging whether monetary policy is indeed slowing real activity (while keeping in mind that long planning and completion times also reduce the response of structures starts to changes in monetary policy).

\section{References}

[1] Asanuma, Masato, and Amy M. Newman-Smith, "Setting Up a Built-in Evaluation System When Sample Design Uses an Imperfect Frame," U.S. Department of Commerce, Bureau of the Census, American Statistical Association Proceeding of the International Conference on Establishment Surveys, 1993.

[2] Bernanke, Ben S., and Alan Blinder, "Credit, Money, and Aggregate Demand," American Economic Review, 1988, 78, 435-39.

\footnotetext{
${ }^{38}$ I note, however, that the introduction of time-to-build, time-to-plan, and ex-post investment inflexibilities leads to few changes in the resulting responses of other variables in the model, the exception being output. Based on this observation, I would conjecture that, if I were to specify a more accurate benchmark model and incorporate time-to-build, time-to-plan, and ex-post investment inflexibilities in investment spending, the contrasting responses of residential and structures investment would still obtain, along with more accurate responses of the other key variables in the model. Addressing this conjecture is an avenue for future research.
} 
[3] Bernanke, Ben S., and Alan Blinder, "The Federal Funds Rate and the Channels of Monetary Transmission," American Economic Review, 1992, 82, 901-21.

[4] Bernanke, Ben S., and Mark Gertler, "Inside the Black Box: The Credit Channel of Monetary Transmission," Journal of Economic Perspectives, 1995, 9, 27-48.

[5] Bernanke, Ben S., Mark Gertler, and Simon Gilchrist, "The Financial Accelerator in a Quantitative Business Cycle Framework," in The Handbook of Macroeconomics, Volume 1C, edited by John B. Taylor and Michael Woodford, North Holland, 1999.

[6] Bernanke, Ben S., Mark Gertler, and Mark Watson, "Systematic Monetary Policy and the Effects of Oil Price Shocks," Brookings Papers on Economic Activity, 1997, 91-142.

[7] Bernanke, Ben S., and Illian Mihov, "Measuring Monetary Policy Shocks," Quarterly Journal of Economics, 1998, 869-902.

[8] Blanchard, Olivier J., and C. M. Kahn, "The Solution of Linear Difference Models under Rational Expectations," Econometrica, 48, 1305-1311, 1980.

[9] Calvo, Guillermo A., "Staggered Prices in a Utility-Maximizing Framework," Journal of Monetary Economics, 1983, 12, 383-398.

[10] Christiano, Laurence J., and Martin Eichenbaum, "Some Empirical Evidence on the Liquidity Effect," in Political Economy, Growth, and Business Cycles, edited by Alex Cukierman, Zvi Hercowitz, and Leonardo Leiderman, MIT Press, 1992.

[11] Christiano, Lawrence J., and Martin Eichenbaum, "Liquidity Effects, Monetary Policy, and the Business Cycle," Journal of Money, Credit, and Banking, 1995, 27, 1113-36.

[12] Christiano, Laurence J., Martin Eichenbaum, and Charles Evans, "Monetary Shocks: What Have We Learned and to What End?," in The Handbook of Macroeconomics Volume 1A, edited by John B. Taylor and Michael Woodford, North Holland, 1999.

[13] Christiano, Laurence J., Martin Eichenbaum, and Charles Evans, "Sticky Price and Limited Participation Models: A Comparison," European Economic Review, 1997, 41, 1173-1200.

[14] Christiano, Laurence J., and Richard M. Todd, "Time-to-Plan and Aggregate Fluctuations," Federal Reserve Bank of Minneapolis Quarterly Review, 1996, Winter, 14-27.

[15] Cogley, Timothy, and James M. Nason, "Testing the Implications of Long-Run Neutrality for Monetary Business Cycle Models," Journal of Applied Econometrics, 1994, 9, S37-S70. 
[16] Cummins, Jason G., Kevin A. Hassett, and R. Glenn Hubbard, "A Reconsideration of Investment Behavior Using Tax Reforms as Natural Experiments," Brookings Papers on Economic Activity, 1994, No. 2, 1-73.

[17] Dixit, Avinash K., and Joseph E. Stiglitz, "Monopolistic Competition and Optimum Product Diversity," American Economic Review, 1977, 67, 297-308.

[18] Gomme, Paul A., Finn E. Kydland, and Peter C. Rupert, "Home Production Meets Time-to-Build," Federal Reserve Bank of Cleveland Working Paper 7, 2000.

[19] Greenwood, Jeremy, and Zvi Hercowitz, "The Allocation of Capital and Time Over the Business Cycle," Journal of Political Economy, 1991, 99, 1188-1214.

[20] Greenwood, Jeremy, Zvi Hercowitz, and Per Krussell, "Long-Run Implications of Investment-Specific Technological Change," American Economic Review, 1997, 87, 34262 .

[21] Greenwood, Jeremy, Richard Rogerson, and Randall Wright, "Household Production in Real Business Cycle Theory," in Frontiers of Business Cycle Research, edited by Thomas F. Cooley, Princeton University Press, 1994.

[22] Hayashi, Fumio, "Tobin's Marginal q and Average q: A Neoclassical Interpretation," Econometrica, 1982, 50, 213-24.

[23] Kiley, Michael T., "Staggered Price Setting and Real Rigidities," Federal Reserve Board Finance and Economics Discussion Series, Working Paper No. 97-46, 1997.

[24] Kimball, Miles S., "The Quantitative Analytics of the Basic Neomonetarist Model," Journal of Money, Credit, and Banking, 1995, 27, 1241-1277.

[25] King, Robert G., Charles I. Plosser, and Sergio T. Rebelo, "Production, Growth, and Business Cycles: I. The Basic Neoclassical Model," Journal of Monetary Economics, 1988, 21, 195-232.

[26] Kydland, Finn E., and Edward C. Prescott, "Time-to-Build and Aggregate Fluctuations," Econometrica, 1982, 50, 1345-1370.

[27] Maffertone, Carol, "Where Dodge Construction Market Analysis Gets Its Start," The Dodge Reporter, 1998, 1-7.

[28] Montgomery, Michael R., "Time-to-Build Completion Patterns for Non-residential Structures, 1961-1991," Economic Letters, 1995, 48, 155-63. 
[29] Montgomery, Michael R., "Time-to-Build Progress Pattern for U.S. Private Nonresidential Structures, 1961-1991," Rivista Internazionale di Scienze Economiche e Commerciali, 1996, 43, 41-62.

[30] Shapiro, Matthew D., "The Dynamic Demand for Capital and Labor," Quarterly Journal of Economics, 1986, 101, 513-42.

[31] Sims, Christopher A., "Interpreting the Macroeconomic Time Series Facts: The Effect of Monetary Policy," European Economic Review, 1992, 36, 975-1011.

[32] Strongin, Steven, "The Identification of Monetary Policy Disturbances: Explaining the Liquidity Puzzle," Journal of Monetary Economics, 1995, 34, 463-97.

[33] U.S. Department of Commerce, Bureau of the Census, "Supplement: Total Time and Monthly Progress from Start of Construction to Completion for Private Non-residential Building and State and Local Construction," Current Construction Reports: Value of New Construction Put in Place, C30/92-10, October 1992.

[34] U.S. Department of Commerce, Bureau of the Census, "Supplement 1: Total Time from Authorization of Construction to Start of Private Residential Buildings," Current Construction Reports: Housing Starts, C20/99-3, March 1999a.

[35] U.S. Department of Commerce, Bureau of the Census, "Supplement 2: Total Time and Monthly Progress from Start of Construction to Completion of Private Residential Buildings," Current Construction Reports: Housing Starts, C20/99-3, March 1999b.

[36] Waggoner, Daniel A., and Tao Zha, "Normalization, Probability Distribution, and Impulse Responses," Federal Reserve Bank of Atlanta Working Paper No. 97-11, 1997.

[37] Yun, Tack, "Nominal Price Rigidity, Money Supply Endogeneity, and Business Cycles," Journal of Monetary Economics, 1996, 37, 345-70.

\section{A Data Appendix}

Although the investment, value put in place, and starts data used in this study come from different sources, the three series are related over the sample period used in the study as a result of how they are constructed.

For most of its history the national accounts estimates of residential investment have been largely based on estimates of residential value put in place, supplemented with data on spending on mobile homes and alterations and additions to existing residential buildings. Similarly, the national accounts measure of structures investment has been largely based 
on estimates of structures value put in place, with estimates of spending on nonresidential farm buildings, utility buildings, and construction in the mining industry also included.

Since 1976, measures of residential and structures value put in place have been closely related to the F.W. Dodge series on residential and structures starts. F.W. Dodge constructs these estimates by closely monitoring the construction industry and recording the commencement of any new building project. In constructing the residential and structures value put in place series, the Bureau of the Census takes a sample of building projects from the F.W. Dodge database and monitors the value of work done on these projects from start to finish. This sample is continuously updated with newly commenced building projects as they appear in the F.W. Dodge building starts database.

Before 1976, however, the series are less closely related. While the Bureau of the Census has always used the F.W. Dodge dataset to construct its sample for Washington D.C. and the 37 most eastern states of the U.S., the sample for the 13 most western states was, prior to 1976, based on building permit data. The more distant relationship between the series over this period is apparent from plots of the data. Since 1976, structures and residential starts have moved very closely with their corresponding value put in place and investment series. Before 1976, however, the movements between the relevant series have been less similar, particularly for the structures series, which have at times displayed some very noticeable divergences (see figure A1). However, even after accounting for their less-related methods of construction, the divergences between these series are surprising and of some concern. Attempts to investigate further why the series move so differently prior to 1976 are hampered by the fact that starts and value put in place are constructed by different institutions. Given my concerns, I choose to work only with the post-1976 sample. ${ }^{39}$ I note, however, that the empirical results that obtain when the sample period is extended back to 1967 are still consistent with the hypothesis that differential project planning and completion times account for the contrasting responses of residential and structures investment.

Hence, despite the fact that the value put in place and starts data all come from different sources, their conceptual similarities over the paper's 1976 to 1996 sample period suggest that we should be able to compare the different responses of starts and value put in place to changes in monetary policy and attribute the differences between the responses as being the result of continuing work on ongoing projects.

\footnotetext{
${ }^{39} \mathrm{~A}$ thorough discussion as to the construction of the value put in place series can be found in Asanuma and Newman-Smith (1993) and Montgomery (1996).
} 


\section{B Log-linearizing the Model's Equilibrium Conditions}

\section{B.1 Log-linearizing the Benchmark Model}

The household's first-order conditions (equations (6) to (11)) log-linearize ${ }^{40}$ to:

$$
\begin{aligned}
& -\widehat{C}_{t}^{Y}+\rho_{c y, k d} \widehat{K}_{t}^{D}+\rho_{c y, h d} \widehat{H}_{t}^{D} \\
& =\widehat{R}_{t}-E_{t} \widehat{C}_{t+1}^{Y}+\rho_{c y, k d} \widehat{K}_{t+1}^{D}+\rho_{c y, h d} E_{t} \widehat{H}_{t+1}^{D}-\widehat{\Pi}_{t+1} \\
& \left(\frac{1}{R^{*}-1}\right) \widehat{R}_{t}=\widehat{C}_{t}^{Y}+-\rho_{c y, k d} \widehat{K}_{t}^{D}-\rho_{c y, h d} \widehat{H}_{t}^{D}-\widehat{\widetilde{M}}_{t} \\
& s\left(\frac{H^{Y *}}{H^{Y *}+H^{D *}}\right) \widehat{H}_{t}^{Y}+\widehat{C}_{t}^{Y}-\rho_{c y, k d} \widehat{K}_{t}^{D}+\left[s\left(\frac{H^{D *}}{H^{Y *}+H^{D *}}\right)-\rho_{c y, h d}\right] \widehat{H}_{t}^{D}=\widehat{\widetilde{\omega}}_{t} \\
& s\left(\frac{H^{Y *}}{H^{Y *}+H^{D *}}\right) \widehat{H}_{t}^{Y}+\left[s\left(\frac{H^{D *}}{H^{Y *}+H^{D *}}\right)-\rho_{h d, h d}\right] \widehat{H}_{t}^{D}-\rho_{h d, c y} \widehat{C}_{t}^{Y}-\rho_{h d, k d} \widehat{K}_{t}^{D}=0 \\
& \left\{\frac{1}{1+\beta \delta_{Y}-\beta}\right\} \widehat{R}_{t}-\left\{\frac{1}{1+\beta \delta_{Y}-\beta}\right\} \widehat{\Pi}_{t+1} \\
& =E_{t} \widehat{\widetilde{\rho}}_{t+1}+\frac{J_{Y}^{-1^{\prime \prime}}(\delta)}{1+\beta \delta_{Y}-\beta}\left(\beta E_{t} \widehat{K}_{t+2}^{Y}-(1+\beta) \widehat{K}_{t+1}^{Y}+\widehat{K}_{t}^{Y}\right) \\
& \left\{\frac{1}{1+\beta \delta_{D}-\beta}\right\} \widehat{R}_{t}-\left\{\frac{1}{1+\beta \delta_{D}-\beta}\right\} \widehat{\Pi}_{t+1} \\
& =\left(\rho_{k d, c y}-\rho_{c y, c y}\right) E_{t} \widehat{C}_{t+1}^{Y}+\left(\rho_{k d, k d}-\rho_{c y, k d}\right) \widehat{K}_{t+1}^{D}+\left(\rho_{k d, h d}-\rho_{c y, h d}\right) E_{t} \widehat{H}_{t+1}^{D} \\
& +\left(\frac{J_{D}^{-1^{\prime \prime}}(\delta)}{1+\beta \delta_{D}-\beta}\right)\left(\beta E_{t} \widehat{K}_{t+2}^{D}-(1+\beta) \widehat{K}_{t+1}^{D}+\widehat{K}_{t}^{D}\right)
\end{aligned}
$$

where $\rho_{x, y}$ are utility function parameters.

The economy's factor demands (equations (17) and (18)) linearize to:

$$
\widehat{K}_{t}^{Y}=\left\{\frac{Y^{*}}{Y^{*}+F C}\right\} \widehat{Y}_{t}+(1-\alpha) \widehat{\widetilde{\omega}}_{t}-(1-\alpha) \widehat{\widetilde{\rho}}_{t}
$$

\footnotetext{
${ }^{40}$ In what follows a caret over a variable signifies the variable's log-deviation from its steady-state value while a star represents the steady-state value of the variable.
} 


$$
\widehat{H}_{t}^{Y}=\left\{\frac{Y^{*}}{Y^{*}+F C}\right\} \widehat{Y}_{t}-\alpha \widehat{\widetilde{\omega}}_{t}+\alpha \widehat{\widetilde{\rho}}_{t}
$$

The log-linearization of equation (16) combined with equation (14) imply that deviations of the gross quarterly inflation rate from its steady-state value of unity evolve according to:

$$
\widehat{\Pi}_{t}=\left\{\frac{(1-\gamma)(1-\gamma \beta)}{\gamma}\right\} \widehat{\widetilde{M C}}+\beta \widehat{\Pi}_{t+1}
$$

The monetary authority's interest-rate feedback rule (equation (19)) and the marketclearing condition (equation (20)) log-linearize to:

$$
\widehat{R}_{t}=\rho_{R} \widehat{R}_{t-1}+\left(1-\rho_{R}\right) \phi_{y} \widehat{Y}_{t}+\left(1-\rho_{R}\right) \phi_{\pi} \widehat{\Pi}_{t}+\varepsilon_{t}
$$

and

$$
\begin{aligned}
\widehat{Y}_{t}= & c \widehat{C}_{t}^{Y}+i^{Y}\left(\frac{1-\delta_{Y}}{\delta_{Y}}\right) \widehat{K}_{t+1}^{Y}-i^{Y}\left(\frac{1}{\delta_{Y}}\right) \widehat{K}_{t}^{Y} \\
& +\left(1-c-i^{Y}\right)\left(\frac{1-\delta_{D}}{\delta_{D}}\right) \widehat{K}_{t+1}^{D}-\left(1-c-i^{Y}\right)\left(\frac{1}{\delta_{D}}\right) \widehat{K}_{t}^{D}
\end{aligned}
$$

where $c$ and $i^{Y}$ are the steady-state shares of output devoted to consumption and investment in market capital.

\section{B.2 Log-linearizing the Model Introducing Time-to-Build, Time-to-Plan and Ex-post Investment Inflexibilities}

Equations (26) and (28) log-linearize to:

$$
\begin{aligned}
E_{t} \widehat{\tilde{\rho}}_{t+2}= & \left\{\frac{1}{\left(1+\beta\left(\frac{I_{2}^{Y *}}{I_{1}^{Y *}}\right)\right)\left(1+\beta \delta_{Y}-\beta\right)}\right\}\left(\widehat{R}_{t}-\widehat{\Pi}_{t+1}\right) \\
& +\left\{\frac{1+\beta \delta_{Y}+\beta\left(\left(\frac{I_{2}^{Y *}}{I_{1}^{Y *}}\right)-1\right)}{\left(1+\beta\left(\frac{I_{2}^{Y *}}{I_{1}^{Y *}}\right)\right)\left(1+\beta \delta_{Y}-\beta\right)}\right\}\left(E_{t} \widehat{R}_{t+1}-E_{t} \widehat{\Pi}_{t+2}\right) \\
& -\frac{J^{-1^{\prime \prime}}\left(\delta_{Y}\right)}{\left(1+\beta \delta_{Y}-\beta\right)}\left(\beta E_{t} \widehat{K}_{t+3}^{Y}-(1+\beta) E_{t} \widehat{K}_{t+2}^{Y}+\widehat{K}_{t+1}^{Y}\right)
\end{aligned}
$$




$$
\begin{aligned}
E_{t} \widehat{\widetilde{\rho}}_{t+1}= & \left\{\frac{1+\beta \delta_{Y}+\beta\left(\left(\frac{I_{2}^{Y *}}{I_{1}^{Y *}}\right)-1\right)}{\left(1+\beta\left(\frac{I_{2}^{Y *}}{I_{1}^{Y *}}\right)\right)\left(1+\beta \delta_{Y}-\beta\right)}\right\}\left(\widehat{R}_{t}-\widehat{\Pi}_{t+1}\right) \\
& -\frac{J^{-1^{\prime \prime}}\left(\delta_{Y}\right)}{\left(1+\beta \delta_{Y}-\beta\right)}\left(\beta E_{t} \widehat{K}_{t+2}^{Y}-(1+\beta) \widehat{K}_{t+1}^{Y}+\widehat{K}_{t}^{Y}\right)-\frac{(\sigma-1)}{\left(1+\beta \delta_{Y}-\beta\right)} \widehat{I}_{2, t}^{Y, t} \\
& +\frac{(\sigma-1)}{\left(1+\beta \delta_{Y}-\beta\right)}\left(\frac{1}{\delta_{Y}}\right) \widehat{K}_{t+1}^{Y}-\frac{(\sigma-1)}{\left(1+\beta \delta_{Y}-\beta\right)}\left(\frac{1-\delta_{Y}}{\delta_{Y}}\right) \widehat{K}_{t}^{Y},
\end{aligned}
$$

while the market clearing condition (equation (29)) log-linearizes to:

$$
\begin{aligned}
\widehat{Y}_{t}= & c \widehat{C}_{t}+i^{Y}\left(\frac{1}{1+\frac{I_{2}^{Y *}}{I_{1}^{Y *}}}\right) \widehat{I}_{1, t}^{Y, t}+i^{Y}\left(\frac{\frac{I_{2}^{Y *}}{I_{1}^{Y *}}}{1+\frac{I_{2}^{Y *}}{I_{1}^{Y *}}}\right) \widehat{I}_{2, t}^{Y, t} \\
& +\left(1-c-i^{Y}\right)\left(\frac{1}{\delta_{D}}\right) \widehat{K}_{t+1}^{D}-\left(1-c-i^{Y}\right)\left(\frac{1-\delta_{D}}{\delta_{D}}\right) \widehat{K}_{t}^{D}
\end{aligned}
$$

where

$$
\begin{gathered}
\widehat{I}_{1, t}^{Y, t}=\left(\frac{1}{\sigma-1}\right)\left(\frac{\left(\frac{I_{2}^{Y *}}{I_{1}^{Y *}}\right) \beta}{1+\left(\frac{I_{2}^{Y *}}{I_{1}^{Y *}}\right) \beta}\right)\left(\widehat{R}_{t}-\widehat{\Pi}_{t+1}\right)+\left(\frac{1}{\delta_{Y}}\right) E_{t} \widehat{K}_{t+2}^{Y}-\left(\frac{1-\delta_{Y}}{\delta_{Y}}\right) \widehat{K}_{t+1}^{Y} \\
\widehat{I}_{2, t}^{Y, t}=\left(\frac{1+\left(\frac{I_{2}^{Y *}}{I_{1}^{Y *}}\right) \beta}{\left(\frac{I_{2}^{Y *}}{I_{1}^{Y *}}\right) \beta}\right)\left(\frac{1}{\delta_{Y}}\right) \widehat{K}_{t+1}^{Y}-\left(\frac{1+\left(\frac{I_{2}^{Y *}}{I_{1}^{Y *}}\right) \beta}{\left(\frac{I_{2}^{Y *}}{I_{1}^{Y *}}\right) \beta}\right)\left(\frac{1-\delta_{Y}}{\delta_{Y}}\right) \widehat{K}_{t}^{Y}+\left(\frac{1}{\left(\frac{I_{2}^{Y *}}{I_{1}^{Y *}}\right) \beta}\right) \widehat{I}_{1, t-1}^{Y, t-1} .
\end{gathered}
$$


Table 1.1 - Average Project Completion Times for Nonresidential Buildings

\begin{tabular}{ccc}
\hline Value of Project (thousands) & Average Number of Months from Start to Completion & Standard Error \\
\hline$\$ 10,000$ or more & 24.7 & - \\
$\$ 5,000$ to $\$ 9,999$ & 17.4 & 0.2 \\
$\$ 3,000$ to $\$ 4,999$ & 14.4 & 0.2 \\
$\$ 1,000$ to $\$ 2,999$ & 11.4 & 0.2 \\
$\$ 250$ to $\$ 999$ & 7.2 & 0.1 \\
Less than $\$ 250$ & 4.1 & 0.1 \\
\hline ALL VALUES & $\mathbf{1 4 . 0}$ & $\mathbf{0 . 1}$ \\
\hline
\end{tabular}

Table 1.2 - Average Project Completion Times for Residential Buildings

\begin{tabular}{|c|c|c|c|}
\hline Type of Project & $\begin{array}{c}\text { Share of Total } \\
\text { Residential Investment* }\end{array}$ & $\begin{array}{l}\text { Average No. of Months: } \\
\text { Permit Issue to Start }\end{array}$ & $\begin{array}{l}\text { Average No. of Months: } \\
\text { Start to Completion }\end{array}$ \\
\hline $\begin{array}{l}\text { Multifamily homes } \\
\text { with } 5 \text { units or more }\end{array}$ & 19.5 to 21 percent & 1.8 & 9.2 \\
\hline $\begin{array}{l}\text { Multifamily homes } \\
\text { with } 2 \text { to } 4 \text { units }\end{array}$ & 2 to 3.5 percent & 1.2 & 7.5 \\
\hline Single-family homes & 77 percent & 0.7 & 6 \\
\hline TOTAL & - & 0.93 to 0.94 & 6.67 to 6.70 \\
\hline
\end{tabular}

Figure 1.1 - Impulse Responses to a Monetary Policy Shock in the Different VAR Systems Panel (a) - Residential Investment (6 Lags) Panel (b) - Structures Investment (6 Lags)
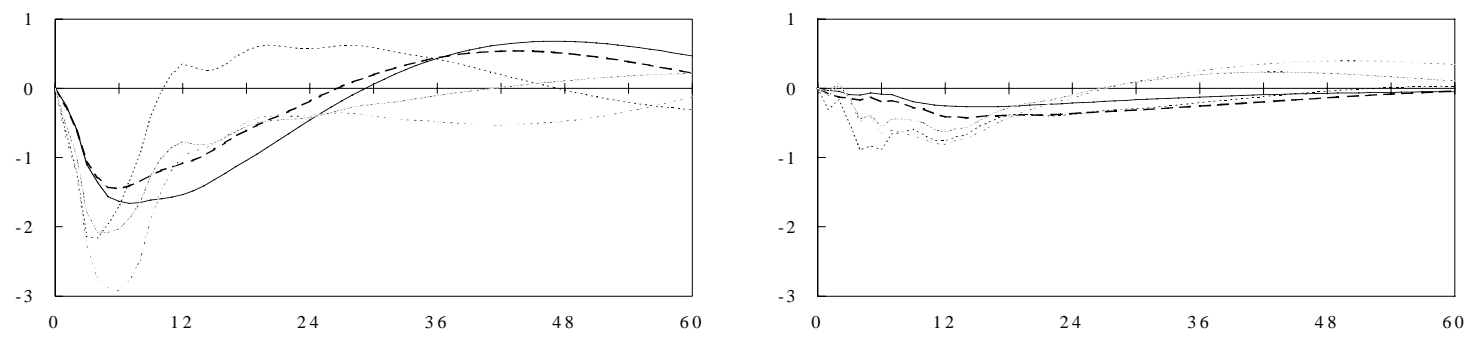

Panel (c) - Residential Value Put in Place (6 Lags) Panel (d) - Structures Value Put in Place (6 Lags)
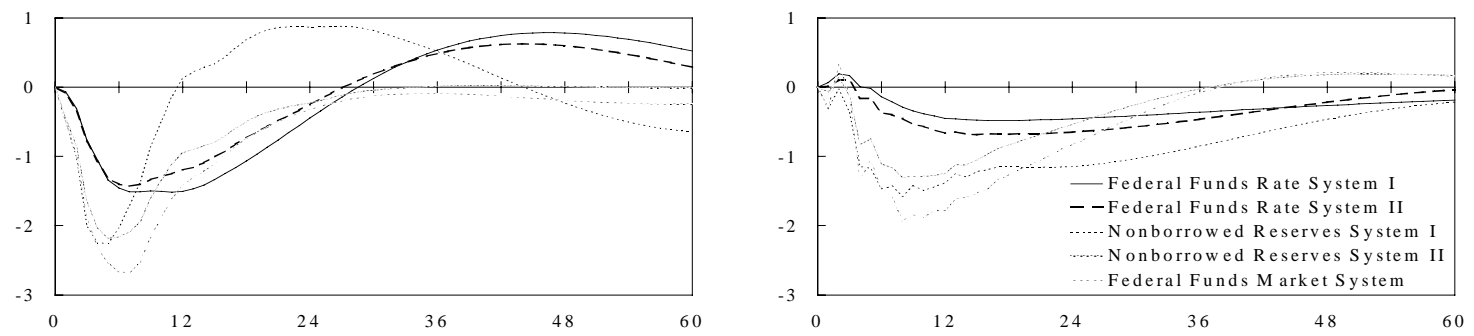

* The range of shares for multifamily homes with 5 or more units and multifamily homes with 2 to 4 units are based on the shares reported in the Housing Starts release (shares of total building projects started) as well the from the shares reported in the F. W. Dodge starts series (shares of total value of building starts). 
Figure 1.2 - Responses to a Monetary Policy Shock in the VAR Models Structures

Residential

Single-Family Units

Panel (a) - Federal Funds Rate I Panel (b) - Federal Funds Rate I Panel (c) - Federal Funds Rate I
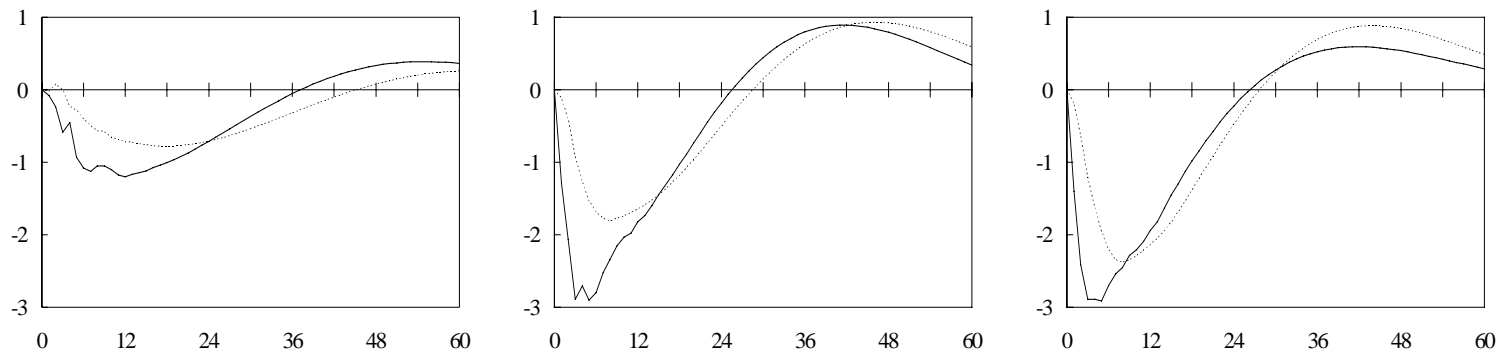

Panel (d) - Federal Funds Rate II Panel (e) - Federal Funds Rate II Panel (f) - Federal Funds Rate II
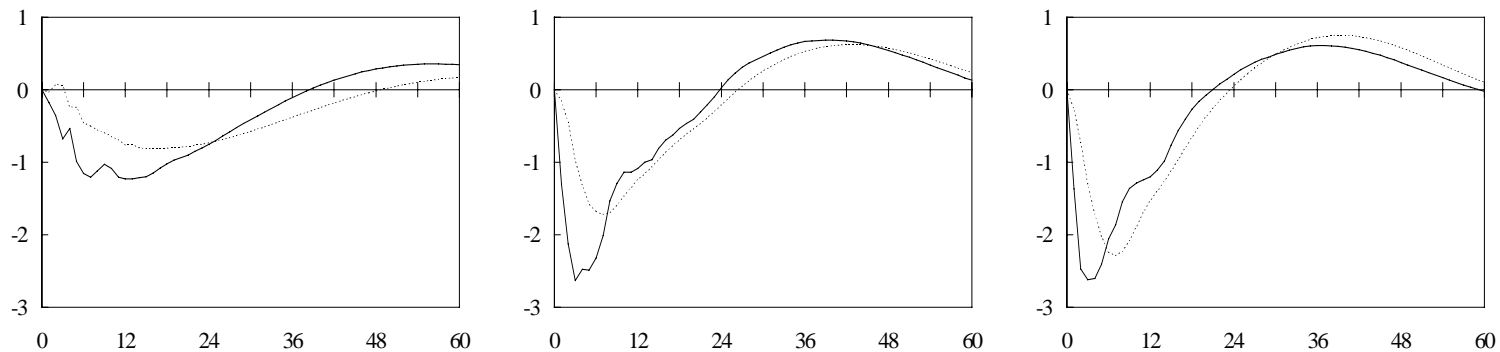

Panel (g) - Nonborrowed Res. I

Panel (h) - Nonborrowed Res. I

Panel (i) - Nonborrowed Res. I
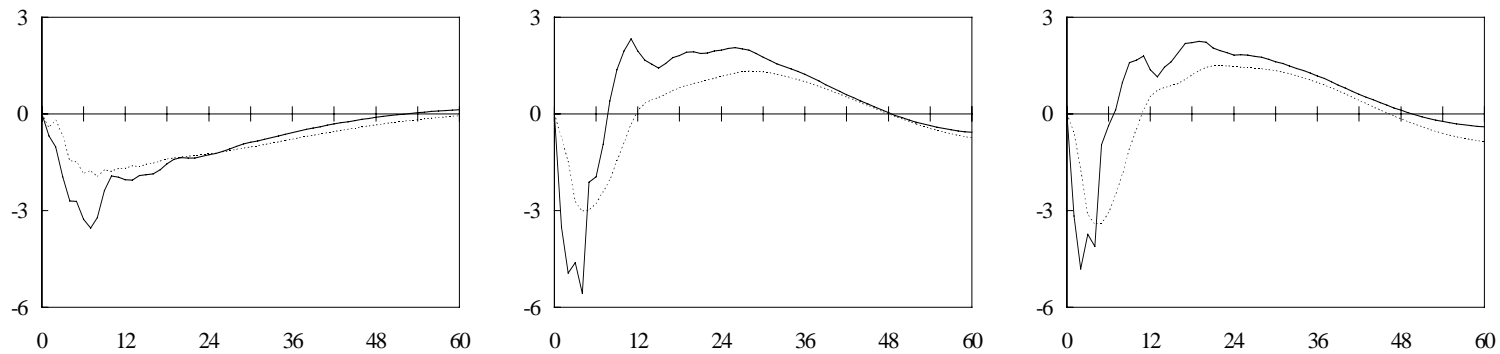

Panel (j) - Nonborrowed Res. II

Panel (k) - Nonborrowed Res. II

Panel (I) - Nonborrowed Res. II
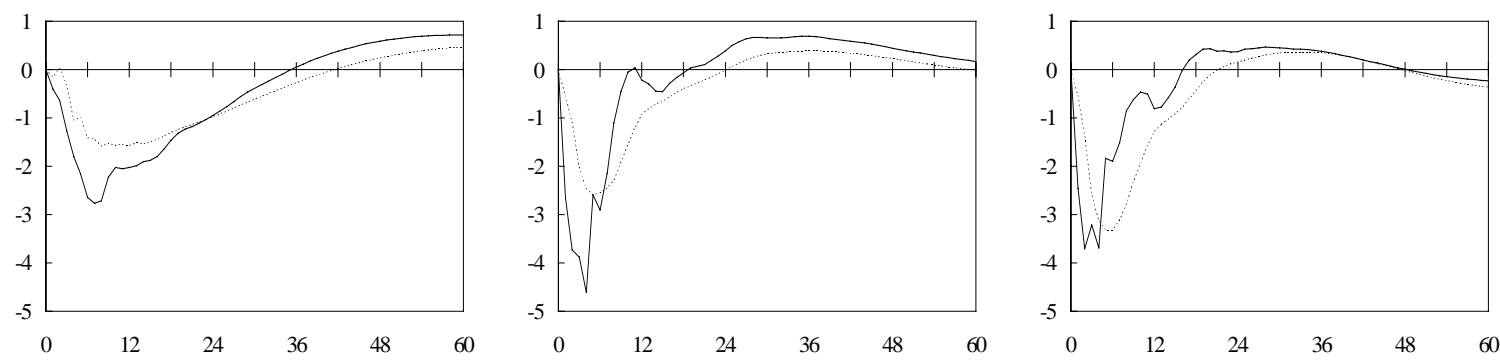

Panel (m) - Federal Funds Mkt.

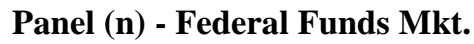

Panel (o) - Federal Funds Mkt.
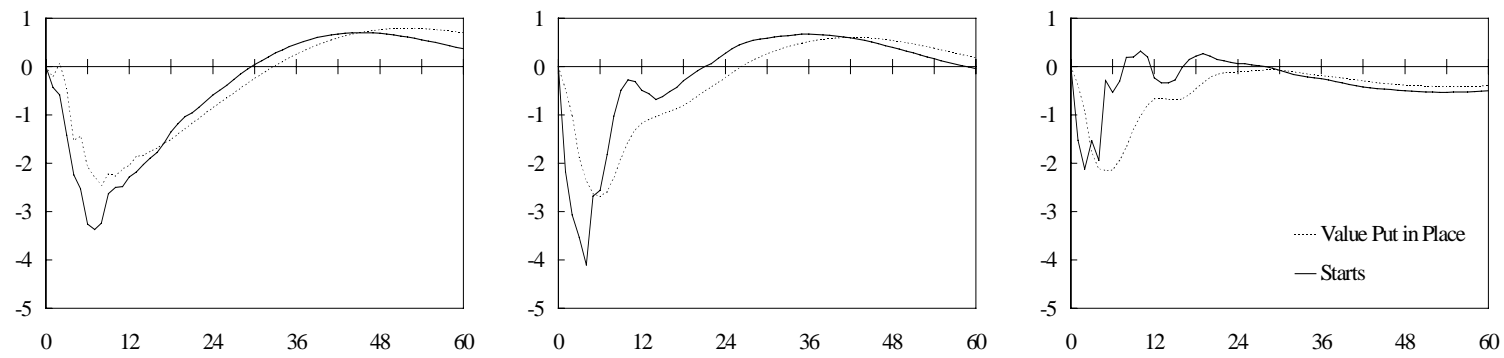
Figure 1.3 - Responses to a Monetary Policy Shock in the Benchmark Model Panel (a) - Nom. Interest Rates

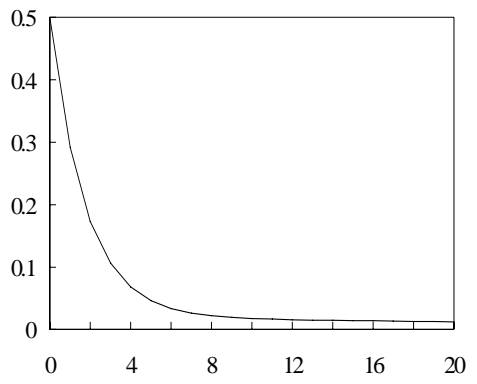

Panel (b) - Inflation

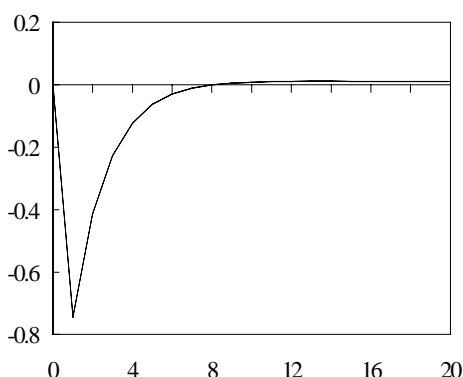

Panel (d) - Output

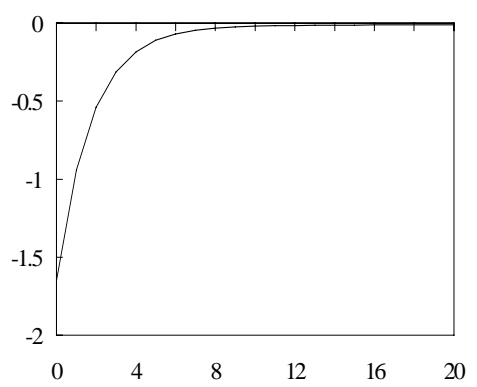

Panel (g) - Consumption
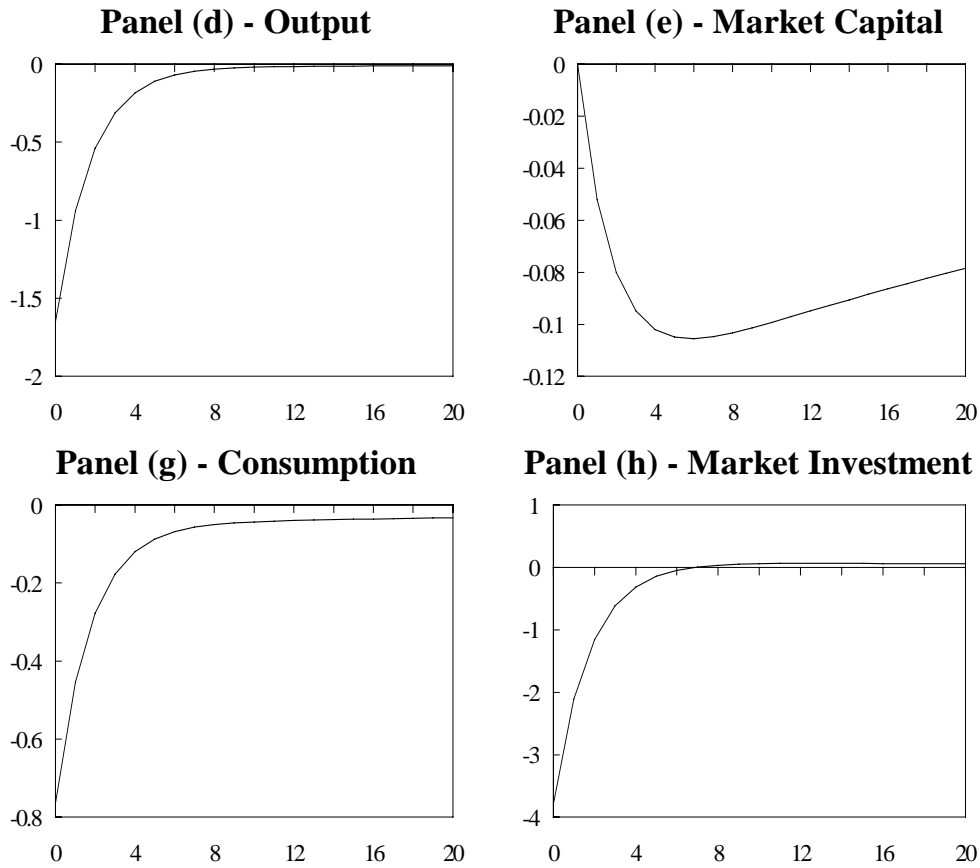

Panel (h) - Market Investment

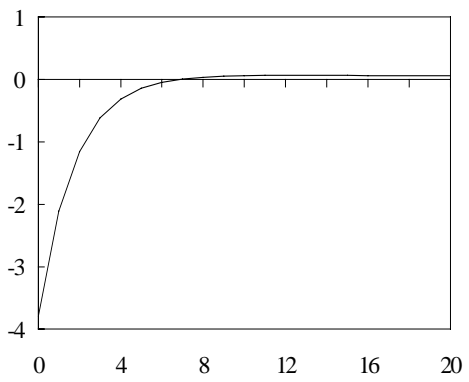

Panel (c) - Real Interest Rates

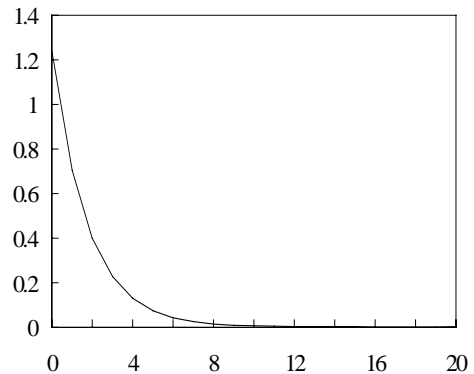

Panel (f) - Domestic Capital

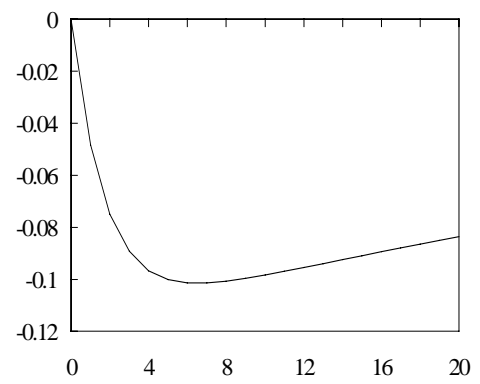

Panel (i) - Domestic Investment

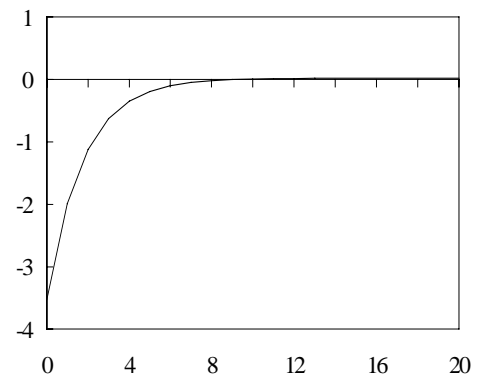

Figure 1.4 - Effect of a Monetary Shock on Market Investment for Various Values of $\sigma$

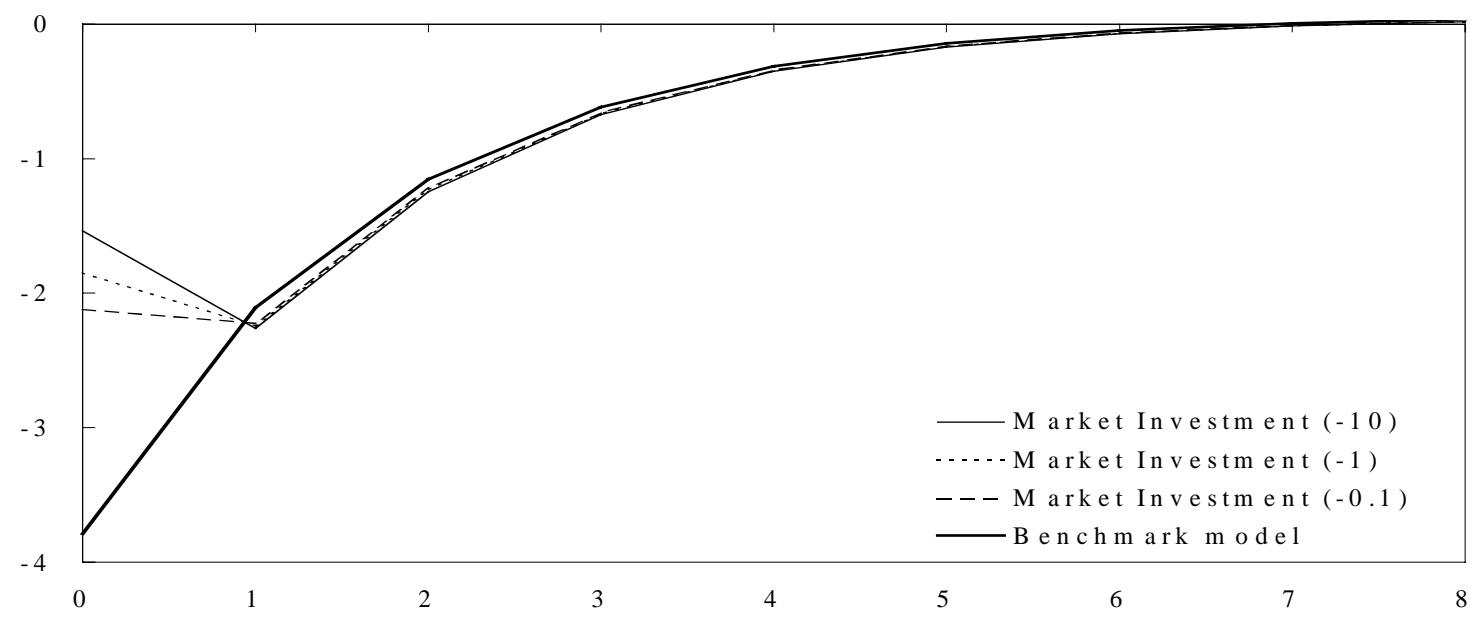


Figure 1.5 - Responses of Market and Household Investment for Various Values of $\sigma$

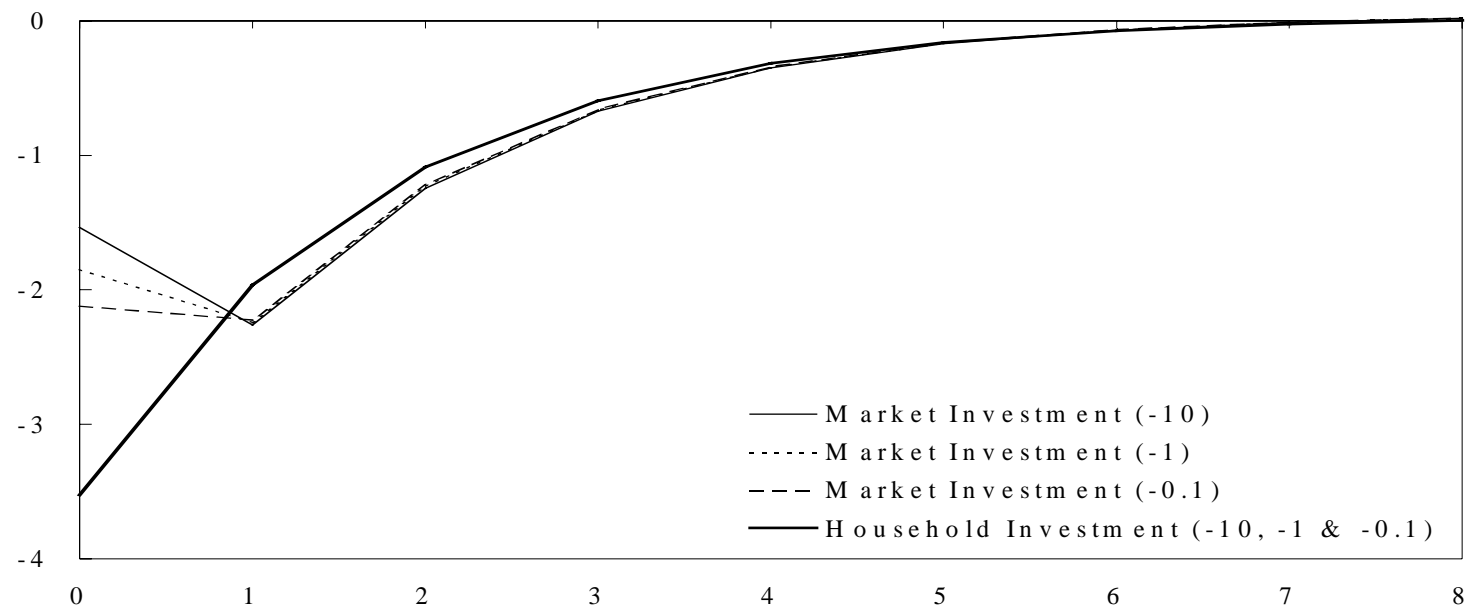

Figure 1.6 - Responses of Market Investment and Starts for Various Values of $\sigma$

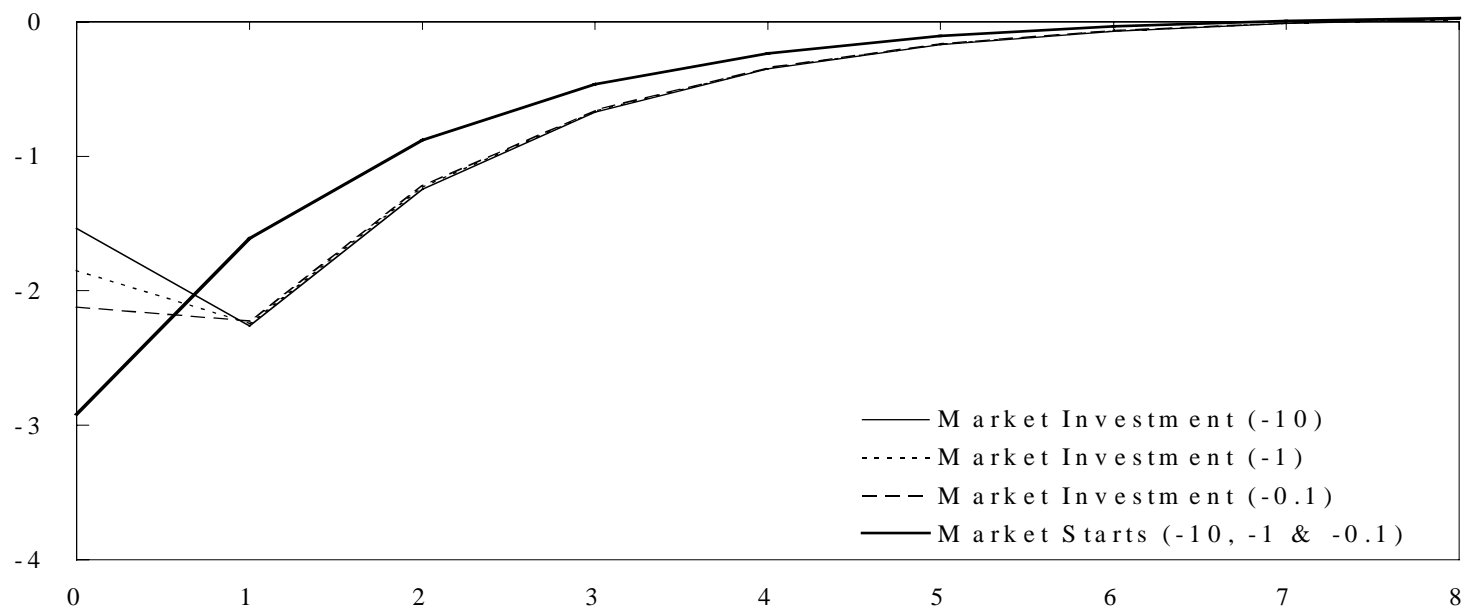

Figure 1.7 - Responses of Starts of Market and Household Capital for Various Values of $\sigma$

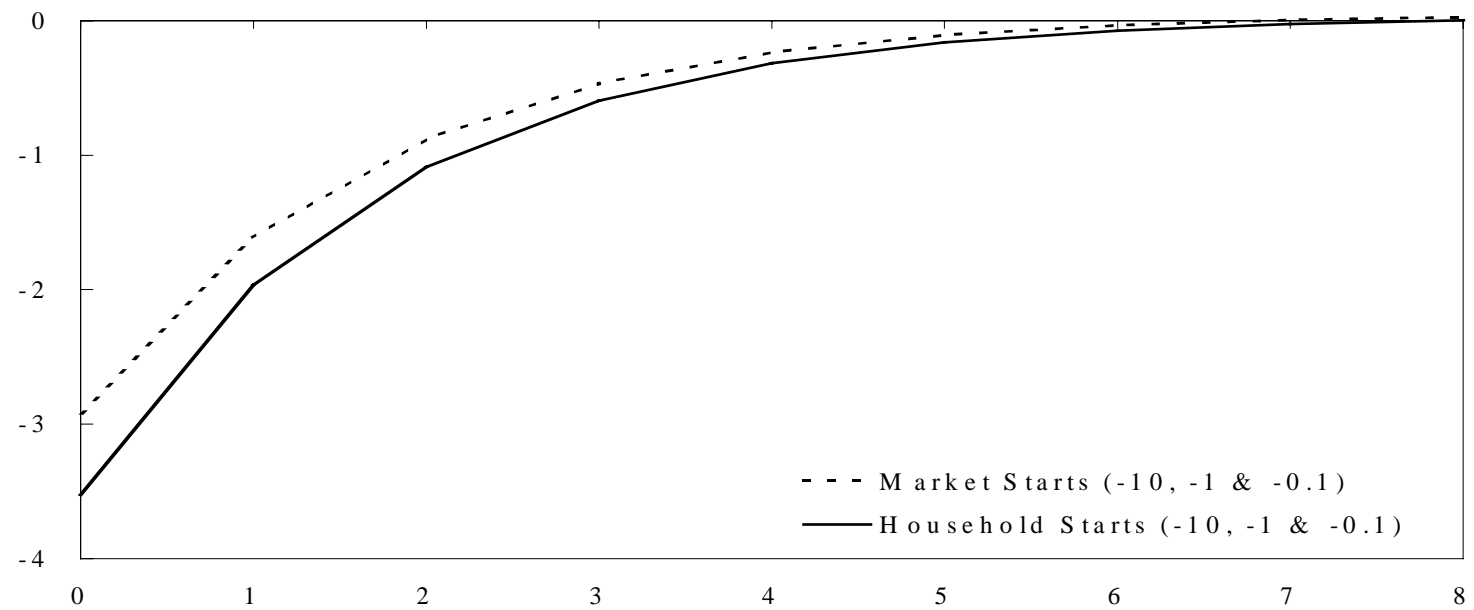


Figure 1.8 - Responses of Starts and Investment in Market Capital

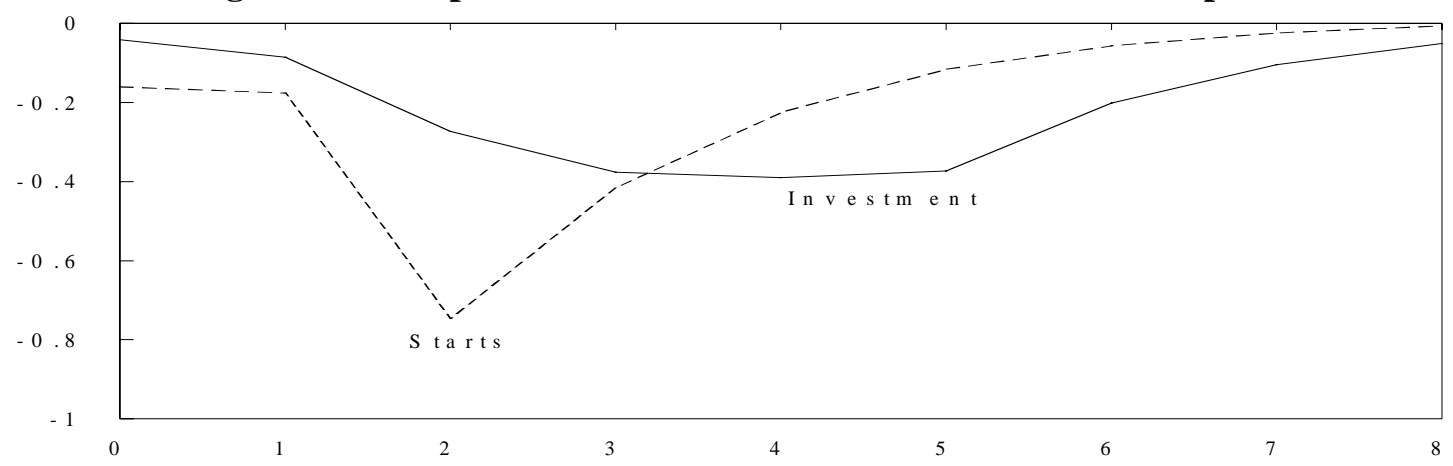

Figure 1.9 - Responses of Starts and Investment in Household Capital

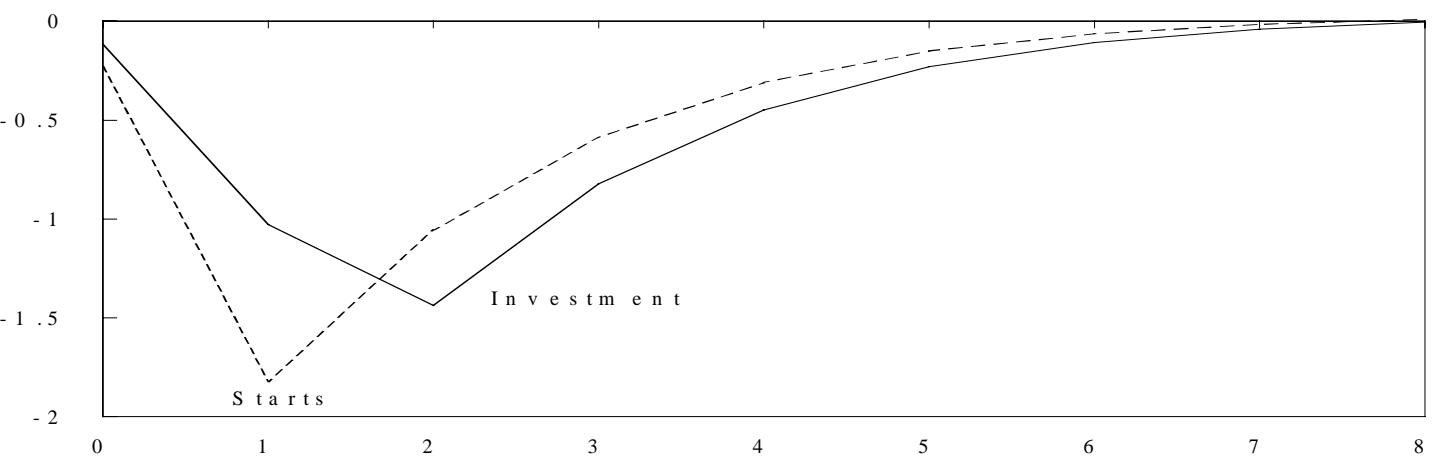

Figure 1.10 - Responses of Starts in Market and Household Capital

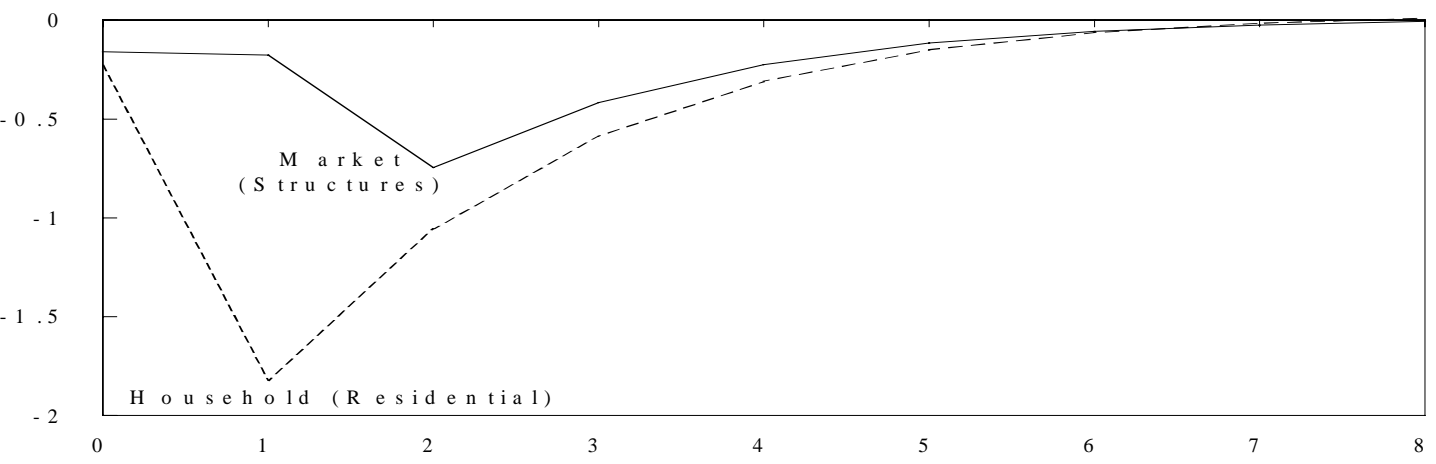

Figure 1.11 - Responses of Investment in Market and Household Capital

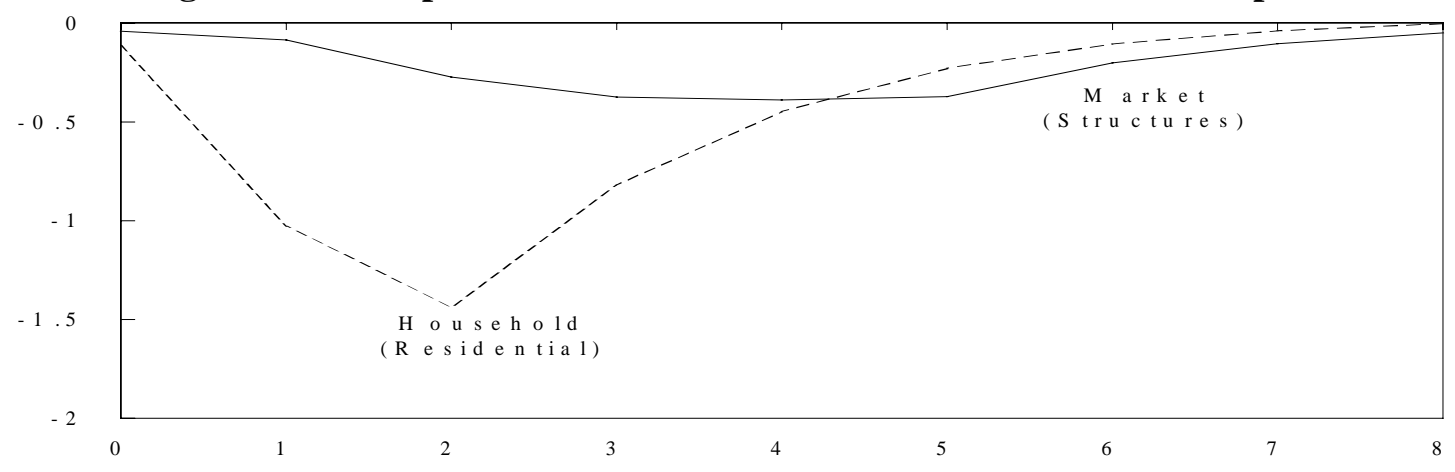


Figure 1.12 - Impulse Responses - Theoretical Model and Federal Funds System I

Panel (a) - Residential Value Put in Place
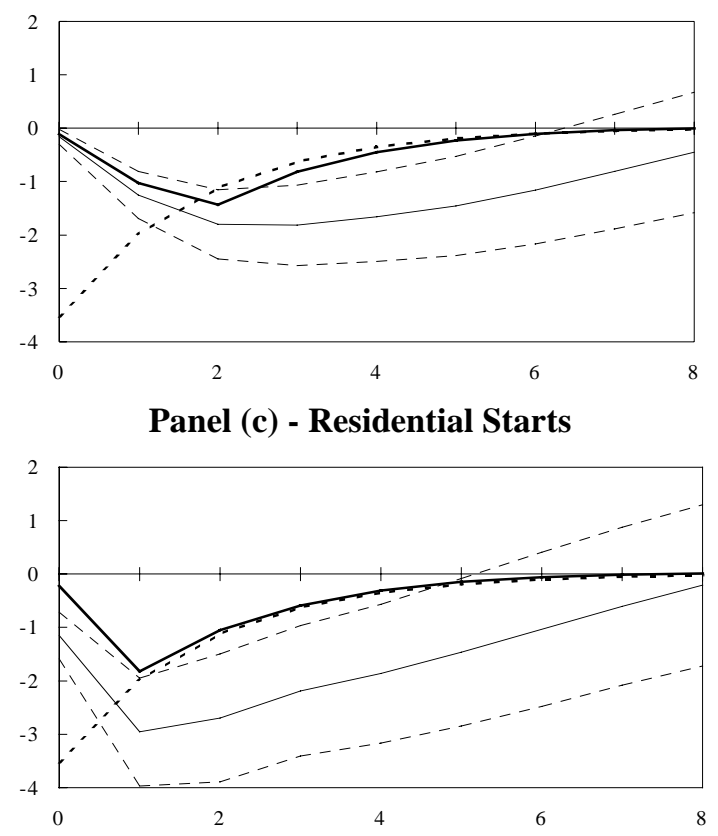

Panel (b) - Structures Value Put in Place

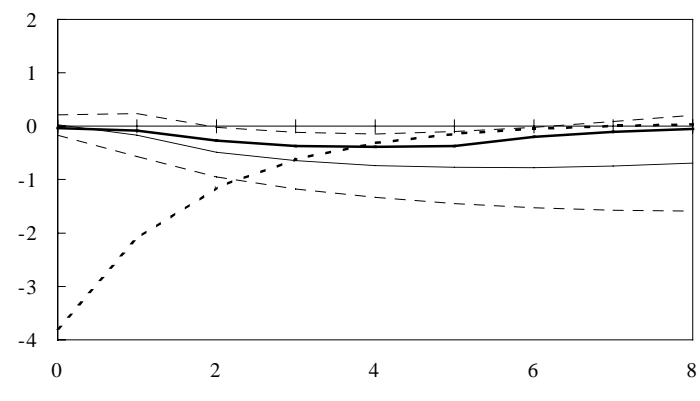

Panel (d) - Structures Starts

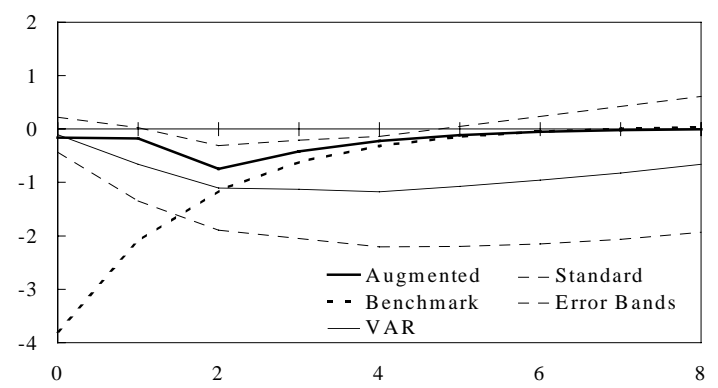

Figure 1.13 - Impulse Responses - Theoretical Model and Federal Funds System II Panel (a) - Residential Value Put in Place

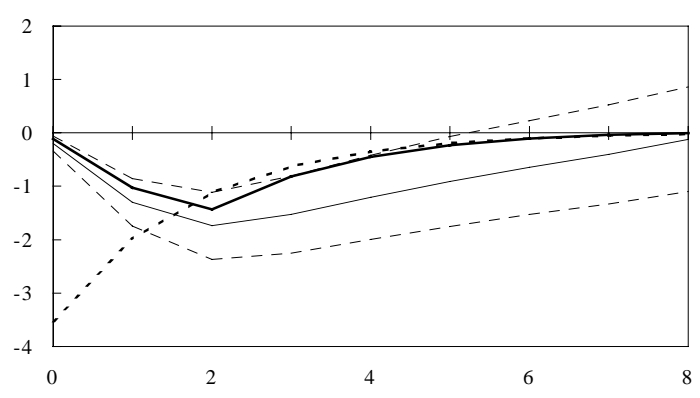
Panel (b) - Structures Value Put in Place

Panel (c) - Residential Starts
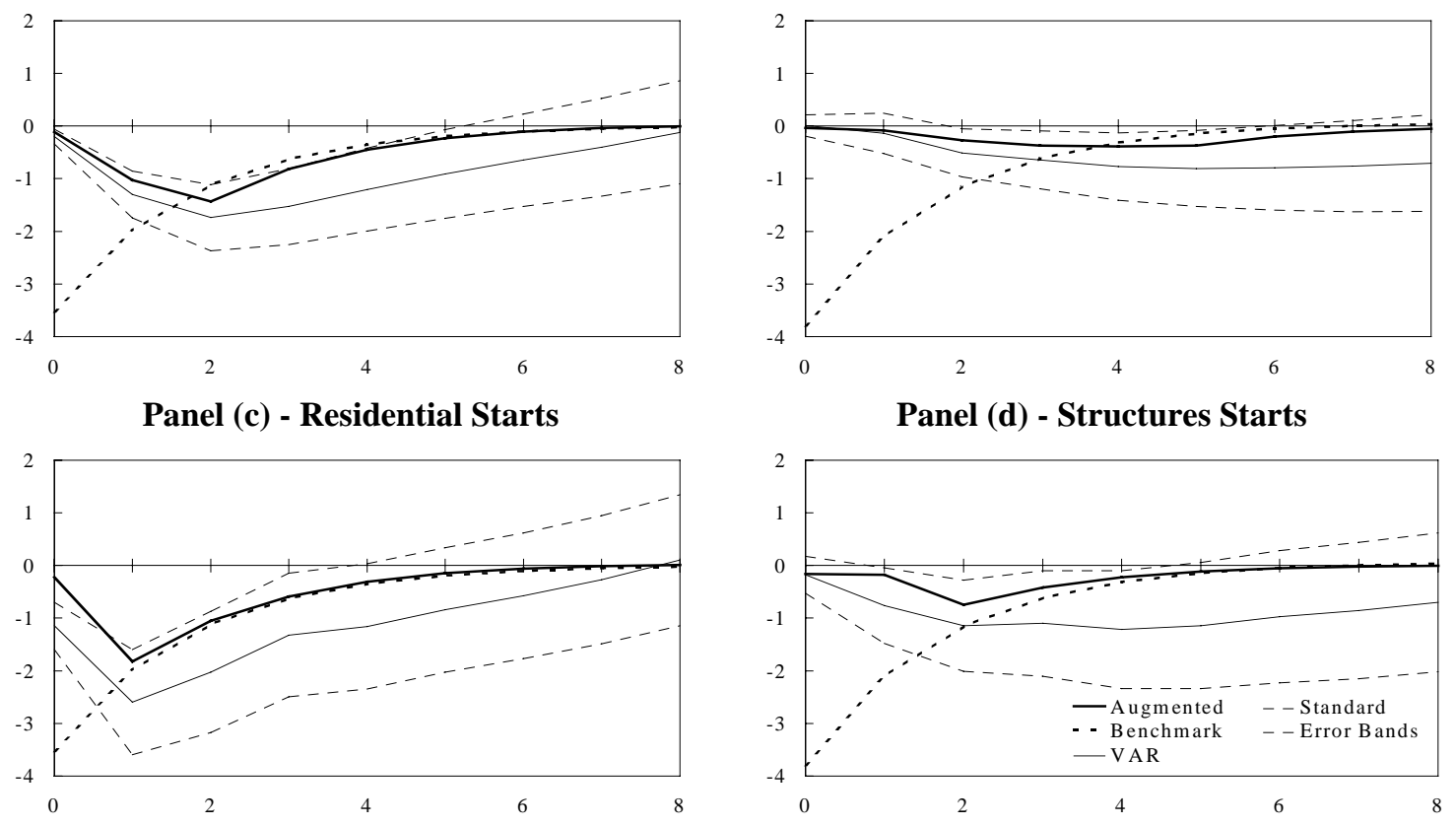
Figure 1.14 - Impulse Responses - Theoretical Model and Nonborrowed Reserves System I

Panel (a) - Residential Value Put in Place

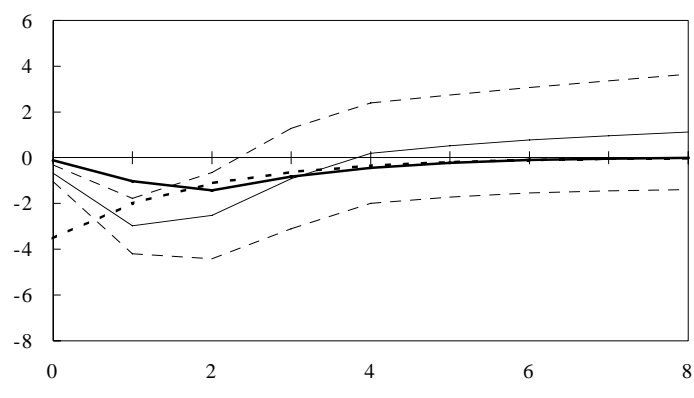

Panel (c) - Residential Starts

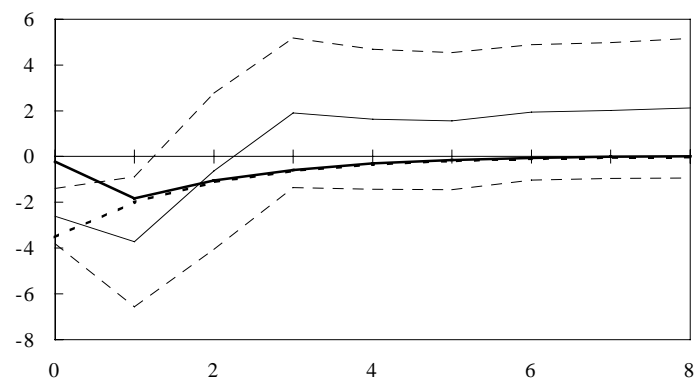

Panel (b) - Structures Value Put in Place

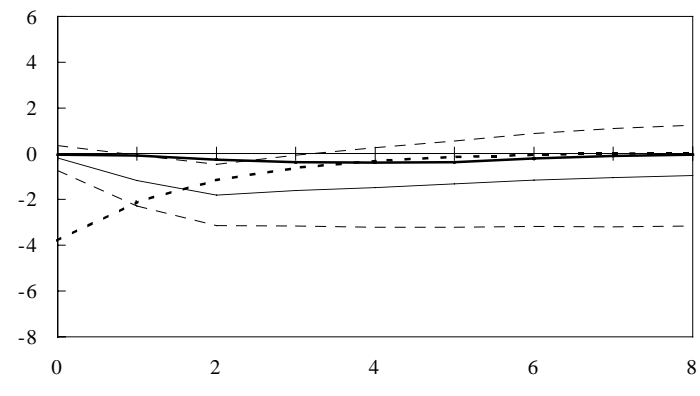

Panel (d) - Structures Starts

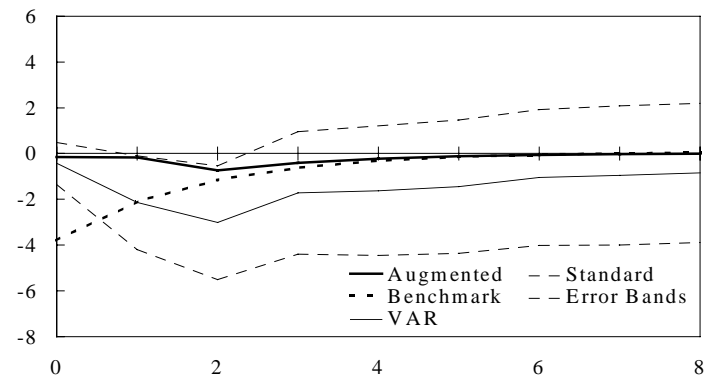

Figure 1.15 - Impulse Responses - Theoretical Model and Nonborrowed Reserves System II

Panel (a) - Residential Value Put in Place

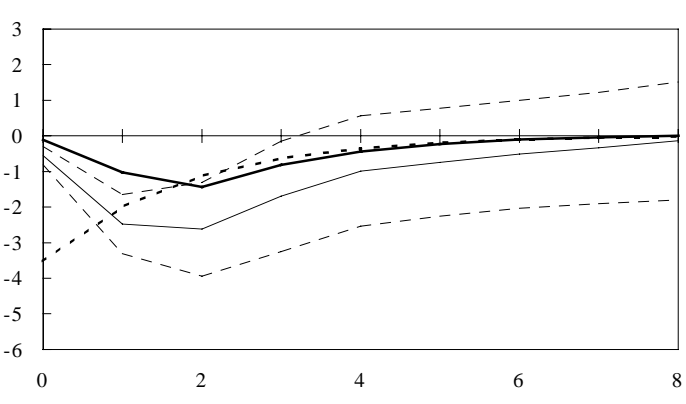

Panel (c) - Residential Starts

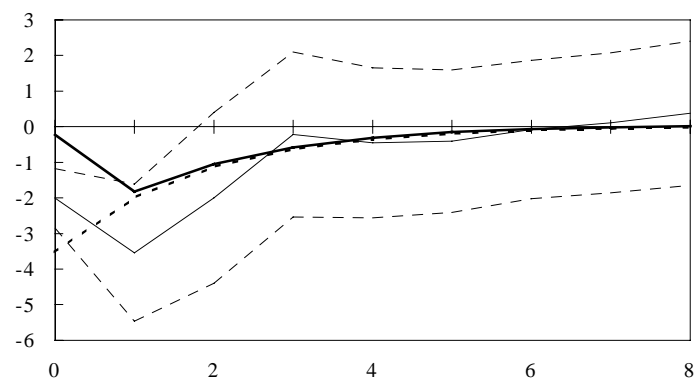

Panel (b) - Structures Value Put in Place

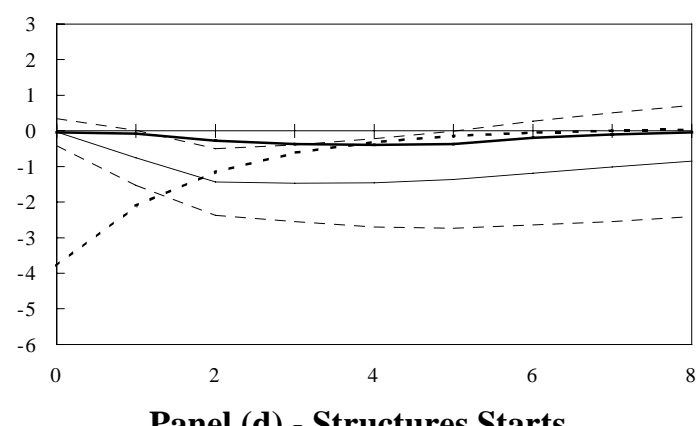

Panel (d) - Structures Starts

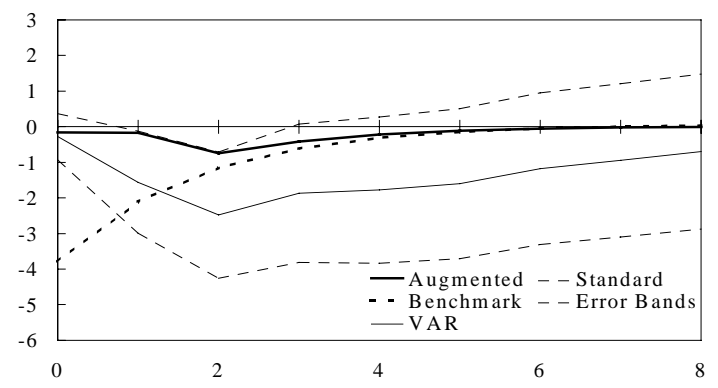


Table 1.3 - Quasi-LM Statistics

\begin{tabular}{lccccc}
\hline & FFRI & FFRII & NBRI & NBRII & FFM* \\
\hline Residential Value Put in Place & & & & \\
\hline Benchmark Model & 4675.89 & 4073.66 & 527.49 & 1152.51 & 638.72 \\
Augmented Model & 18.45 & 10.67 & 19.05 & 19.98 & 1.67 \\
\hline Residential Starts & & & & \\
\hline Benchmark Model & 322.11 & 281.08 & 25.06 & 57.20 & 26.58 \\
Augmented Model & 32.75 & 31.32 & 26.99 & 29.62 & 2.72 \\
\hline Structures Value Put in Place & & & & 130.39 \\
\hline Benchmark Model & 2482.55 & 2162.61 & 291.60 & 634.79 & 0.77 \\
Augmented Model & 26.08 & 8.26 & 7.33 & 9.55 & 34.62 \\
\hline Structures Starts & & & & & 0.81 \\
\hline Benchmark Model & 925.44 & 838.04 & 122.65 & 245.27 & 8.30 \\
Augmented Model & 13.04 & 11.37 & 8.27 & & \\
\hline
\end{tabular}

\section{Figure 1.16 - Structures Starts and Value Put in Place}

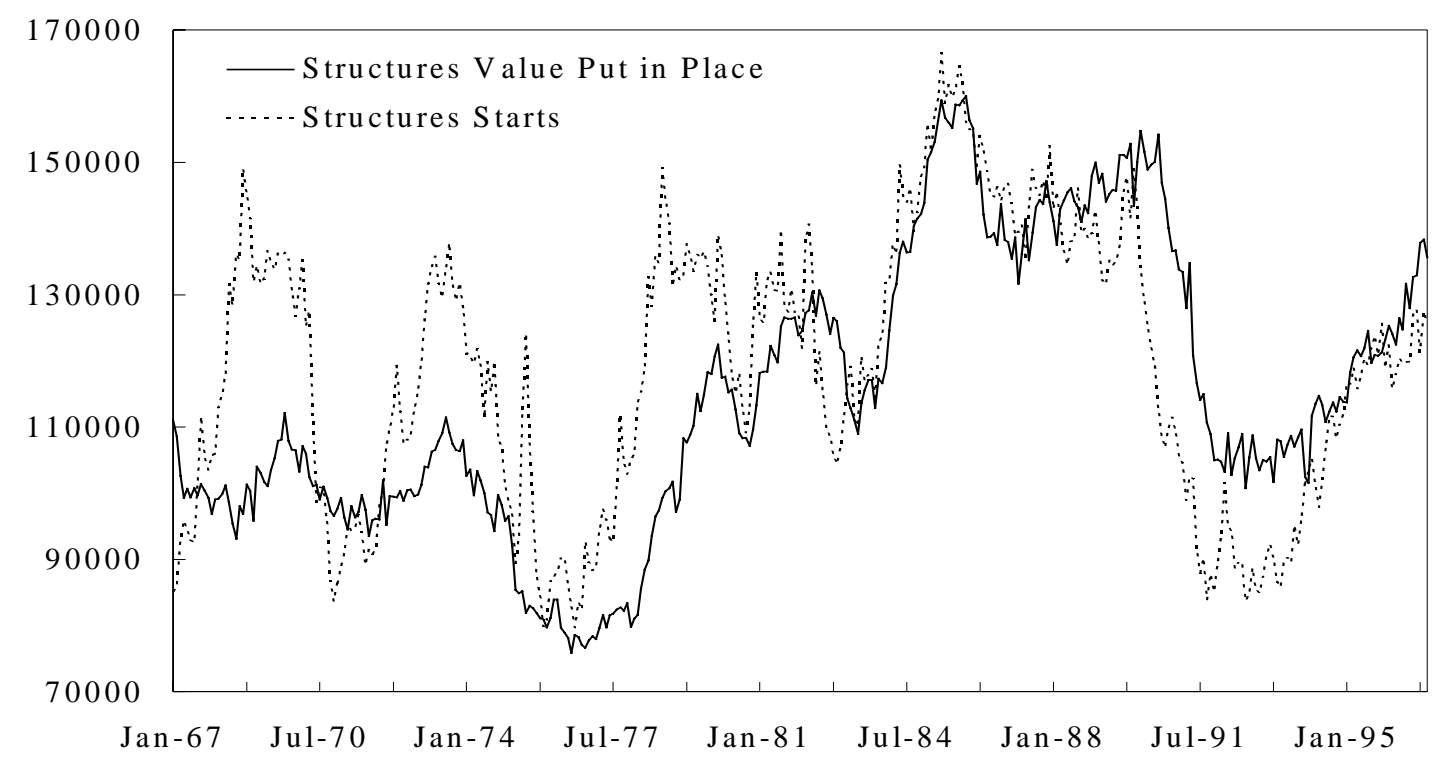

* The Quasi-LM statistics associated with the Federal funds market system of monetary policy identification are small due to the enormous standard error bands associated with the impulse response functions implied by this method of identification. 